Rev. Biol. Neotrop. 10 (2) : 33 - 51. 2013

\title{
RUtos de Trigoniaceae E SEU USO NA tAXonomia
}

\section{JoÃo Rodrigues Miguel}

Universidade do Grande Rio (UNIGRANRIO), Rua Prof. José de Souza Herdy, 1160, Centro, CEP 25071-220, Duque de Caxias, Rio de Janeiro, Brasil. Bolsista da PROPESQ/FUNADESP. jmiguel@unigranrio.com.br.

\section{Elsie Franklin Guimarães}

Instituto de Pesquisas Jardim Botânico do Rio de Janeiro (JBRJ), Rua Pacheco Leão, 915, Jardim Botânico, CEP 22460-038, Rio de Janeiro, Brasil. Bolsista do CNPq.

\section{Ariane luna Peixoto}

Instituto de Pesquisas Jardim Botânico do Rio de Janeiro (JBRJ), Rua Pacheco Leão, 915, Jardim Botânico, CEP 22460-038, Rio de Janeiro, Brasil. Bolsista do CNPq.

Resumo: O estudo das Trigoniaceae revelou que os caracteres morfológicos de seus frutos podem contribuir, de maneira decisiva, na identificação em níveis genérico, específico e infraespecífico. Os gêneros Trigoniastrum Miq., Humbertiodendron Leandri e Isidodendron Fern-Alonso, Pérez \& Idarraga, caracterizam-se por apresentar fruto sâmara, enquanto Trigonia Aubl. e Trigoniodendron E.F. Guim. \& Miguel apresentam cápsulas. A coleta e análise de materiais frutificados, bem como a analise de extensas coleções de herbário, permitiram observar que a origem, deiscência, indumento, replum e dispersão constituem fatores diagnósticos para os táxons infrafamiliares. Neste trabalho os frutos são descritos e incluídos em grupos morfológicos. Chaves para identificação dos gêneros, espécies e variedades são apresentadas bem como ilustrações dos principais tipos de frutos.

Palavras-chave: Carpologia, Morfologia, Taxonomia

Palavras-chave: Carpologia, Morfologia, Taxonomia.

AвstRAct: The study of the Trigoniaceae revealed that the morphological characteristics of its fruits can contribute, in a decisive manner, to the identification of its gender both at a generic, specific or even an infra-specific level. The genus Trigoniastrum Miq, Humbertiodendon Leandri and Isidodendron Fern-Alonso, Pérez \& Idarraga, are characterized by the presence of one samara, while Trigonia Aubl and Trigoniodendron E.F. Guim \& Miguel present the trigonal or rounded capsule. The collecting and analysis of fruit material allowed us to observe that origin, dehiscence, indument, replum and dispersion constitute diagnostic factors. This work aims to characterize the fruits and use them in the taxonomy of the species. It includes engraved plates, and the description of each fruit, emphasizing the types of dehiscence; it also presents dichotomic keys identification.

KEY words: Carpology, Morfology, Taxonomy.

\section{INTRODUÇÃO}

As Trigoniaceae foram descritas por Endlicher $(1840,1841)$ e tem seu nome com base em Trigonia Aubl., que apresenta cápsula trigonal, uma de suas principais características. Alguns estudiosos evidenciaram o tipo e forma da cápsula (Aublet, 1775; Lamarck, 1786, 1787; Vahl, 1798), a posição da semente (Cambessèdes, 1829, 1830) ou a consistência do endocarpo e abertura das valvas (Warming, 1875; Petersen, 1896). Lleras (1978) ao estudar a família, destacou os frutos. Guimarães \& Miguel (1985) quando do conhecimento das Trigoniaceae do estado do Rio de Janeiro informam os diferentes aspectos da deiscência das cápsulas e estabelecem dois grupos 
de espécies nos quais foram colocados os táxons a eles pertinentes com base em caracteres das cápsulas. Barroso et al. (1999) ressaltam as informações já citadas por seus antecessores e relatam das placentas que formam seis feixes com valvas deles pendentes.

Família com distribuição pantropical e centro de diversidade na Amazônia; é constituída pelos gêneros Humbertiodendron Leandri endêmico de Madagascar (Leandri, 1949) e Trigoniastrum Miq., endêmico de Sumatra, na Indonésia (Van Steenis, 1948, apud Lleras, 1978); os neotropicais Isidodendron Fern-Alonso, Pérez \& Idarraga endêmico da Colômbia, na América do Sul (Fernandez-Alonso et al. 2000); Trigonia, distribuído nas três Américas e Trigoniodendron E.F. Guim. \& Miguel do Brasil, na América do Sul (Guimarães \& Miguel, 1987).

O uso de caracteres carpológicos para a identificação de exemplares de Trigoniaceae tem sido de grande auxílio. Entretanto, ainda não existe registro na literatura que mostre o conjunto das variações morfológicas e estruturais dos frutos e das sementes. Este trabalho objetiva a análise destas estruturas para, através de chaves analíticas, contribuir na identificação dos táxons.

\section{Material e métodos}

Observações no campo foram realizadas durante a coleta de exemplares; analisaram-se amostras em frutos, depositadas nas coleções dos herbários listados abaixo por seus acrônimos, segundo Thiers (2009): ALCB, B, BHCB, BM, BR, C, CEN, CESJ, CEPEC, CH, CVRD, EAC, F, FUEL, G, GOET, GFJP, GUA, HB, HBR, HRB, HUEFS, IAN, IBGE, INPA, IPA, IPEAN, JPB, K, MBM, MBML, MEXU, MG, MO, NY, P, PAMG, PEUFR, R, RB, RFA, RUSU, S, SP, SPF, U, UEC, US, USP, VEN, VIC, VIES e W. As descrições seguem a ordem alfabética; o material foi denominado de: examinado quando toda coleção foi citada, e de selecionado quando apenas uma parcela foi mencionada. Todos os espécimes estudados são apresentados no índice de coletores.

Para a descrição e classificação dos frutos tomou-se por base a consistência, o indumento, disposição dos septos, medidas de aberturas das valvas, comprimento a largura como também a orientação da deiscência.

As informações de Trigoniastrum hypoleucum Miq. foram obtidas da literatura e da foto do tipo(http://plants.jstor.org/specimen/ 10677710?s=t. Maio./2013). Não foram descritas com detalhes Trigonia bracteata Lleras, da Venezuela (Barinas, Steymarck \& Rabe, 96588 holótipo U; isótipo US, VEN.); T. coppenamensis Stafleu, do Suriname (Coppename, Maguire 24857 holótipo $U$, foto do Isótipo NY!); $T$. costanensis Steyermarck \& Badilho, da Venezuela, (Yaracuy, north of Nirgua, Madrix 37 foto holótipo NY!); T. subcymosa Benth. da Guyana (Schomburgk,
56 foto isótipo NY!) e $T$. echiteifolia Rusby, da Bolívia, La Paz, Bang 2812 foto MO!, NY!) tendo em vista que os exemplares tipos e outras coleções às quais se teve acesso não apresentaram frutos ou quando presentes, encontravam-se em estágio muito jovem, impossibilitando a elaboração de descrições e posicionamento dos mesmos nos grupos estabelecidos.

Optou-se por citar os exemplares tipos das espécies estudadas, mesmo que não apresentassem frutos. Para cada espécie foram citados exemplares testemunhos. Os espécimes examinados encontram-se reunidos em um único item, ordenado por seus coletores, número de coleta, sendo que, o número indicado corresponde ao primeiro, salvo quando os mesmos apresentam seus respectivos números.

As abreviaturas do texto correspondem: ca. (cerca de), c.d. (coletor desconhecido), ms.m. (metros acima do nível do mar), n.v. (não visto), s.d (sem data),s.l (procedência desconhecida), s.n (sem número de coletor).

Para a confecção das chaves analíticas além do fruto foram utilizados outros caracteres que se encontram assinalados na descrição dos gêneros ou nos comentários. Os desenhos foram confeccionados com o auxílio do microscópio estereoscópio com câmara clara, em diferentes escalas de aumento.

\section{Resultados e Discussão}

TRIGONIACEAE Endl., Ench. bot. 570. 1841.

Árvores ou arbustos com ramos eretos, flexuosos, às vezes escandentes. Estípulas interpeciolares, caducas ou persistentes. Folhas simples, opostas ou alternas, margem inteira, plana ou revoluta. Inflorescências axilares ou terminais, simples ou compostas, com brácteas e bractéolas ovadas a lanceoladas, geralmente assimétricas. Flores diclamídeas, hermafroditas, zigomorfas; pétalas 5, uma externa, o estandarte que apresenta giba globosa ou nasiforme; duas laterais espatuladas com tufo de tricomas na base, raro glabras; duas internas carenadas; estames 6-7; estaminódios presentes até quatro ou faltam; filetes concrescidos na base constituindo um anel estaminal que envolve o gineceu, geralmente provido de duas glândulas lobadas ou laciniadas; ovário súpero, 3-4 locular; óvulos numerosos; estilete terminal; estigma globoso, bilobado ou trilobado. Frutos tipo cápsulas triloculares, septicidas, com cálice persistente ou sâmaras trialadas. Sementes em número variável, anemocóricas, envolvidas por tricomas castanhos ou amarelados, sedosos, enovelados; endosperma parco, carnoso; embrião plano, ovoide, oblongo, cotilédones crassos e planos.

Esta pesquisa resultou na observação do material carpológico de 28 espécies diferenciadas pelos caracteres contidos na chave: 
1. Fruto sâmara trialada

2. Folhas alternas

3. Sâmara com alas unidas na porção basal, livres no ápice.

4. Trigoniastrum hypoleucum

3 '. Sâmara com alas unidas desde a porção basal até o ápice................. Isidodendron tripterocarpum

$2^{\prime}$. Folhas opostas 1. Humbertiodendron saboureaui

$1^{\prime}$. Fruto cápsula

4 Cápsulas uniloculares

5 Folhas com tricomas; anel estaminal com estaminódios.....

3.8. Trigonia hypoleuca

5 `. Folhas glabras; anel estaminal sem estaminódios. 3.24. T. virens

4'. Cápsulas triloculares

6. Cápsulas com replum formando seis cordões pendentes; deiscência concomitante nas duas extremidades; valvas presas pelos repluns no terço superior

7. Folhas em fascículos.

3.6. T. fasciculata

7 . Folhas opostas

8. Folhas com tricomas amarelados na face abaxial

9. Sépalas glandulosas na margem.

3.7. T. floccosa

$9^{\prime}$. Sépalas não glandulosas na margem

10. Folhas glandulosas na face adaxial.

3.20. T. sericea

$10^{`}$. Folhas não glandulosas na face adaxial....

3.23. T. villosa

$8^{\prime}$. Folhas com tricomas alvos ou acinzentados na face abaxial

11. Folhas acinzentadas na face abaxial.

3.13. T, nivea

11 '. Folhas alvas na face abaxial

12. Folhas arredondadas ou subarredondadas

3.17. $T$. rotundifolia

12 '. Folhas ovadas, obovadas, elípticas ou oblongo-elípticas

13. Subarbustos.

3.4. T. cipoensis

13'. Lianas

14. Brácteas, bractéolas e sépalas papiloso-glandulares.

3.16. T. reticulata

14'. Brácteas, bractéolas e sépalas não papiloso-glandulares

15. Cápsula até $7 \mathrm{~cm}$ compr.

16. Anel estaminal com 3 - 4 estaminódios; sementes com tricomas enovelados

3.13. T. nivea

16'. Anel estaminal sem estaminódios; sementes com tricomas eretos.

3.22. T. spruceana

15'. Cápsula com mais de $7 \mathrm{~cm}$ de compr.

17. Inflorescência em racemos; flores com pedúnculos até $0,5 \mathrm{~mm}$ compr., pétala espatulada pilosa na base.

3.9. T. killipii

17'. Inflorescência em tirsos; flores com pedúnculos além de 0,5mm compr., pétala espatulada glabra na base

18. Epicarpo rufo-viloso na face interna

3.3. T. candelabra

18 '. Epicarpo glabro, reticulado na face interna

3.15 T. prancei

6'. Cápsulas com replum imperceptível ou perceptível ereto; deiscência do ápice para a base;valvas presas pela base

19. Arbusto escandente; folhas opostas; anel estaminal com 3-4 estaminódios; Cápsula alongada

20. Inflorescências em racemos simples.

3.21 T. simplex

20'. Inflorescência em racemo duplo, panícula ou tirso

21. Epicarpo com protuberâncias

22. Endocarpo de ápice bífido, com tricomas

22'. Endocarpo de ápice não bífido, glabro.

3.19. T.rytidocarpa

21 . Epicarpo liso, desprovido de protuberâncias

3.2. T. boliviana

23. Fruto adulto com epicarpo alvo-pubescente

3.10. T. laevis

23'. Fruto adulto com epicarpo glabro

24. Folhas membranáceas; frutos $2,0-3,5 \mathrm{~cm}$ compr.

25. Glândulas do anel estaminal lobadas....

3.18. T. rugosa

25'. Glândulas do anel estaminal multilaciniadas ....

3.11. T. littoralis

$24^{\prime}$. Folhas não membranáceas, frutos menor que 2,5 compr.

26. Cápsula com dorso em seção transversal anguloso.

27. Cápsula com epicarpo alvo-pubescente, lenticelado na face externa. . .

3.1. T. bahiensis

27'. Cápsula com epicarpo flavo-pubescente, reticulado-verrucoso na face externa.

3.14.T. paniculata

26. Cápsula com dorso em seção transversal arredondado

28. Inflorescência duplo racemo, cápsula de 1,0-1,3 cm compr., epicarpo cinério esverdeado, sementes 4-5 por valva com tricomas enovelados.

3.5. T. eriosperma

28'. Inflorescência tirso; cápsula de 0,5-0,8 cm, epicarpo castanho; sementes 1-2 por valva com tricomas eretos.

3.12. T. microcarpa

$19^{\prime}$. Árvore, folhas alternas; anel sem estaminódios; cápsula arredondada.

5. Trigoniodendron

spiritusanctense 
1. Humbertiodendron Leandri. Compt. Rend. Hebd. Séances Acad. Sci.Paris. 229:847. 1949. Tipo: Madagascar, próximo a Ambila, 21.II.1948, Ramarokoto 1522 fl. (Holótipo P; Fotografia do Isótipo MO!). Fig. 1, a-d.

Sâmara 1,8-2 x 1,8 - 2,2 cm, elíptica a arredondada, triangular em seção transversal, base arredondada, subcordada, ápice obtuso, apiculado, trialada, alas unidas na parte central, livres entre si, coriáceas, castanhas, multinervadas; epicarpo castanho, piloso na face externa com retículo saliente na face interna; mesocarpo aderente ao epicarpo; endocarpo castanho-claro, coriáceo, tomentoso. Gênero monotípico.

1. H. saboureaui Leandri, Compt. Rend. Hebd. Séances Acad. Sci.Paris. 229:847. 1949. Tipo: Madagascar, próximo a Ambila, 21.II.1948, Ramarokoto 1522 (Holótipo P; Fotografia do Isótipo MO!).

Apresenta folhas opostas e habita as florestas de Madagascar.

Espécimes selecionados: Madagascar, 8-10. VIII.1957, R. Capuron 18059SF (P).

2. Isidodendron Fern-Alonso, Pérez-Zabala \& Idarraga, Revista Acad. Colomb. Ci. Exact. 24(92): 348-354, f. 1-4. 2000. Tipo: Puerto Parra, $8 \mathrm{~km}$ S. de Campo Capote, Cabrera 823, (Fotografia do Holótipo, Col.!; Isótipo NY).

Sâmara 4-7 x 2,5-4 cm, oblongo-elíptica, emarginada na base e no ápice, trialada, alas unidas desde a porção basal até o ápice, membranáceas, estriadas, lanosas, formando ângulos de 120 graus entre elas. Sementes 1-3 por fruto, ca. $2 \times 1,5 \mathrm{~cm}$. (fide Fern-Alonso, Pérez \& Idarraga, 2000). Gênero monotípico.

\section{I. tripterocarpum Fern-Alonso, Perez \& Idarraga \\ Dispõe de folhas alternas e habita bosques tropicais, primários ou secundários da Colômbia.}

3. Trigonia Aubl., Hist. PI. Guiane 1:387, Ícones 149. 1775. Tipo: GUIANA FRANCESA. Cayenne, 1775, Aublet S.n. (Lectotipo BM!). Fig. 2: a - o.

Cápsula trilocular raro tetralocular, septos completos ou incompletos; trivalvar, septicida, forma e tamanho variável, oblonga, elíptica a lanceolada, ápice arredondado, agudo a abruptamente acuminado, cálice persistente; epicarpo liso, verrucoso, rugoso, com nervuras ou protuberâncias; indumento variável na face externa; mesocarpo, quando presente formando tênue linha, de coloração castanha, aderente ao epicarpo; endocarpo livre ou aderente, coriáceo a papiráceo, glabro ou com indumento; valvas naviculares, inteiras a fendidas no ápice. A deiscência ora ocorre do ápice para a base, ora concomitante nas extremidades; presença de replum perceptível ereto, às vezes, imperceptível, livre ou aderente ao endocarpo, ou constituem seis cordões de onde pendem as valvas que apresentam os funículos, persistentes ou não, quando da abertura. Sementes de uma a muitas por valva, com tamanhos variados; testa delicada, profusamente envolvida por tricomas castanhos ou amarelados, sedosos, curtos-eretos (equinados), longos ou enovelados, variáveis no comprimento; endosperma parco, carnoso; embrião plano, ovóide, oblongo, alvo, crasso, eixo hipocótilo-radícula cilíndrico, cotilédones elípticos, arredondados, cordados, carnosos.

Arbustos ou lianas com folhas opostas ou verticiladas, com distribuição Neotropical.

3.1. Trigonia bahiensis E. F. Guim, Miguel \& Fontella, Bol. Mus. Bot. Municip. 36:1-4. 1979. Tipo: BRASIL. Bahia: Seabra, 13-IX-1956, Pereira 2163 (Holótipo RB!).

Cápsula trilocular, trivalvar, deiscência do ápice para a base, elíptica, dorso em seção transversal anguloso, base atenuada, ápice truncado-apículado, coriácea, castanha, 1,5-2,1 x 0,5-1,0 cm; epicarpo alvo-pubescente, lenticelado na face externa, glabro, reticulado na face interna; endocarpo aderente, castanho, coriáceo, ápice bífido, glabro na face interna, parede lateral castanha, coriácea, lisa; replum ereto, castanho-claro; funículos 3-4; valva navicular, dorso em seção transversal arredondado, abertura 0,5-0,7 cm; sementes 3-4 por valva, arredondadas, tricomas $0,8-1,0 \mathrm{~cm}$ compr., enovelados a eretos, castanhos.

Arbusto com folhas opostas e cartáceas, que se desenvolve em floresta de Mussununga sobre solo arenoso, coletada no Brasil, nos estados do Ceará, Bahia, Minas Gerais e Espírito Santo.

Espécimes examinados: BRASIL. Ceará: Carrasco, 1996, F.S. de Araújo s.n (EAC, RB 324059); Bahia: Porto Seguro, Reserva Florestal de Porto Seguro, Estrada Municipal 7,35 km, 12.I.90, D.A. Foll 1062 (CVRD); Minas Gerais: Juramento, Estr. de Mocambinhos/Janaúba, s.d., H. Saturnino 463 (RB); Espírito Santo: Linhares, Reserva Florestal da CVRD km 0, 23.III.86, $M$. Sobral 4754 (CVRD).

3.2. Trigonia boliviana Warm., Mart. Fl. bras. 12(2):134. 1875. Tipo: BOLÍVIA: s.d., Cuming 214 (Holótipo W!, Isotipo F).

Cápsula trilocular, trivalvar, deiscência do ápice para a base, ovado-elíptica, base arredondada, ápice agudo, longo-apiculado, coriácea; castanho-esverdeada, 1,5-3 x 0,5-1,5 cm; epicarpo pubescente a glabrescente, com protuberâncias e lenticelas na face externa, glabro, com saliências na face interna; endocarpo aderente, castanho, coriáceo, ápice inteiro, às vezes, com uma pequena fenda, glabro na face interna, parede lateral, castanha, coriácea, lisa; replum ereto, castanho; funículos 8-9; valva navicular, dorso em seção transversal arredondado, abertura 0,5-0,6 $\mathrm{cm}$; sementes 8-9 por valva, elípticas, tricomas 0,7-1 cm compr., enovelados, castanhos. 


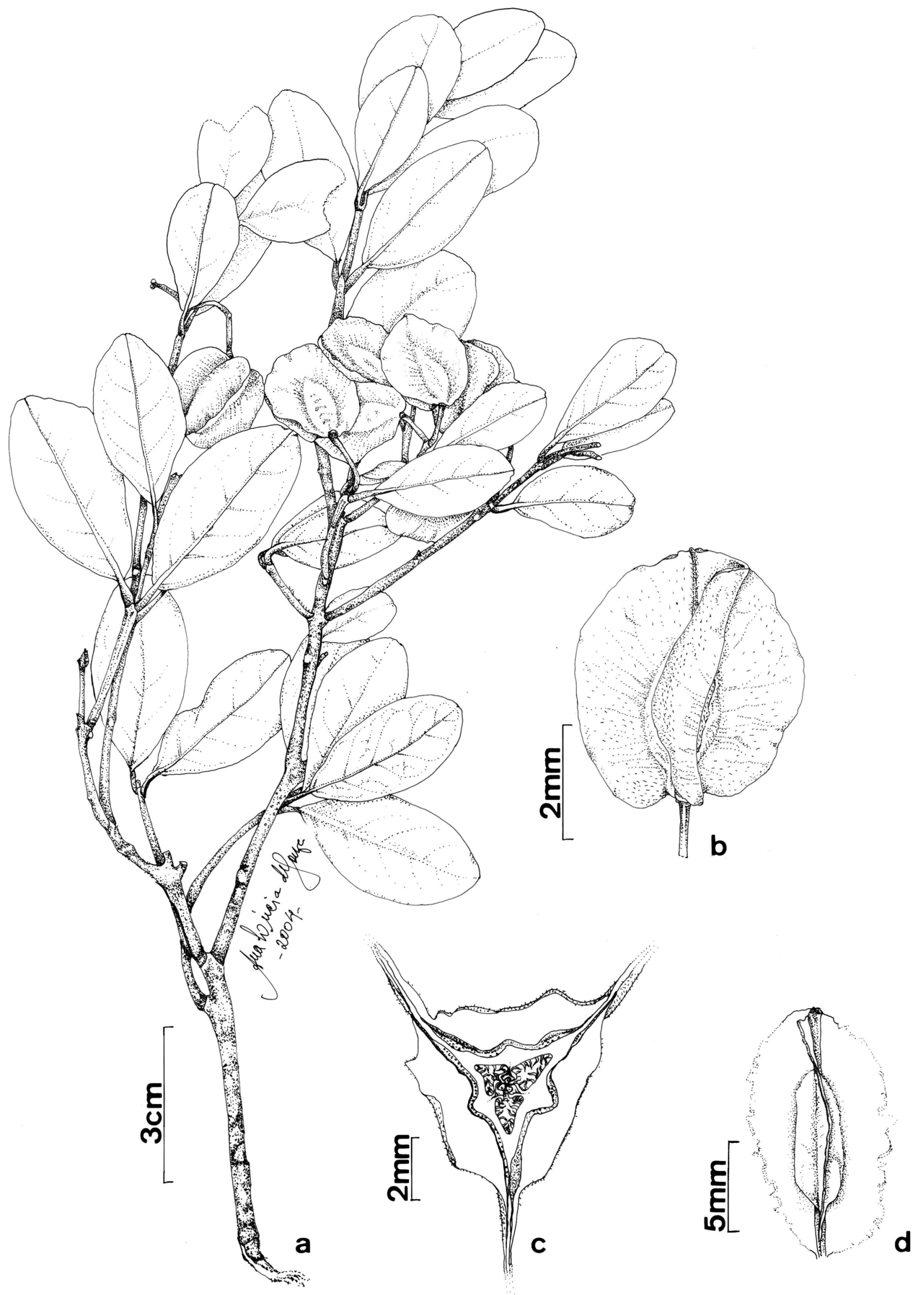

Figura 1 - Espécie de Trigoniaceae com sâmara: Humbertiodendron saboureaui Leandri. a. ramo frutifero. b. sâmara. c. visão transversal. d. visão longitudinal. (Madagascar, 8-10.VIII.1957, R. Capuron 18059SF (P)). 

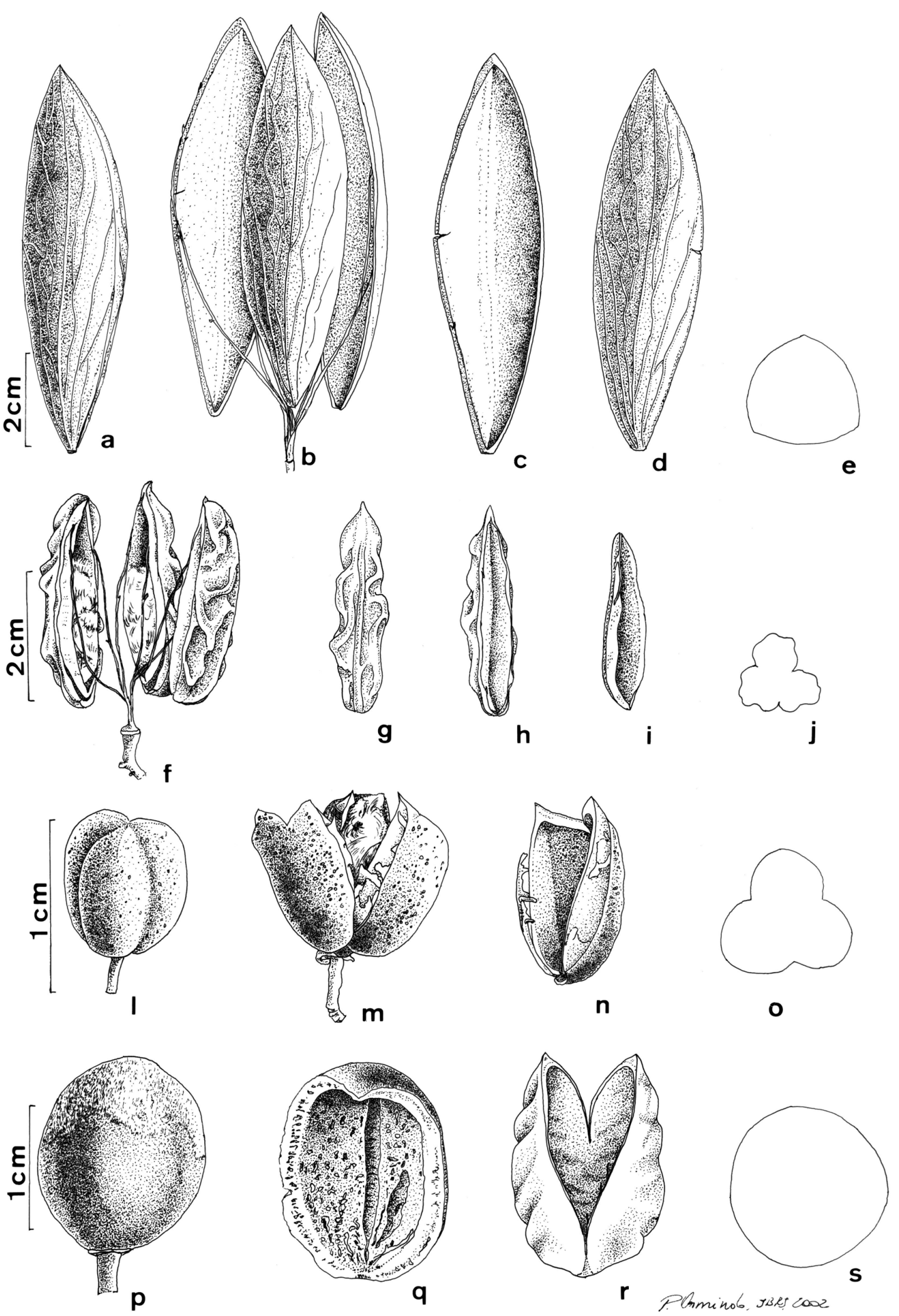

Figura 2 - Espécies de Trigoniaceae com cápsula: a - e. Trigonia virens Macbr. a. cápsula fechada. b. deiscência e replum. c, d. visão interna e externa da valva. e. visão transversal. $f$ - j. Trigonia nivea Cambess. var. nivea. f. deiscência e replum. g - h. visão externa e interna da valva. i. endocarpo livre. j. visão transversal. I - o. Trigonia eriosperma (Lam.) Fromm. et Santos. I. cápsula fechada. m. cápsula aberta. n. epicarpo e endocarpo. o. visão transversal. p - s. Trigoniodendron spiritusanctense E. F. Guim. \& Miguel. p. cápsula fechada. q. epicarpo. r. endocarpo. s. visão transversal. 
Arbusto com folhas opostas, bicolores, de pilosa a glabra na face adaxial; amareladas, tomentosas a glabrescente na abaxial; flores em panícula. Cresce na Bolívia e no Brasil, nos estados de Mato Grosso, Minas Gerais e Rio de Janeiro. Frequente nos bosques de Yungas na Bolívia, vale com vegetação densa; no Brasil ocorre na floresta estacional decidual e ombrófila densa.

Espécimes examinados: BOLÍVIA: 1929, J. Steinbach 8132 (F, G, MO, S); BRASIL. Mato Grosso, Corumbá, morro do Cristo Redentor, 4.XII.1984, C.A.C. Ferreira 1654 (RB); Rio de Janeiro: Petrópolis, Estrada do Contorno \pm 700 m s.m, 23.3.1968, D. Sucre 2513 et al. (CEN, GUA, RB).

3.3. Trigonia candelabra Lleras, Flora Neotrópica Monogr. 19:41, fig.14-15. 1978. Tipo: SURINAME. Brokopondo: at edge of secundary forest, s.d., J. van Donselaar 2812 (Holótipo U!).

Cápsula trilocular, trivalvar, deiscência concomitante nas duas extremidades, obovado-lanceolada, base aguda, ápice agudo, coriácea, castanha, 6,5-8 x 0,8-1,5 cm; epicarpo rufo-viloso, liso nas faces externa e interna; endocarpo aderente, glabro internamente; parede lateral cartilaginosa; replum não visto; valva navicular, dorso, em seção transversal, arredondado; sementes subglobosas, tricomas longos, enovelados, castanhos.

Espécie caracterizada pelas inflorescências em tirsos com aspecto de candelabro; flores com pedúnculo além de $0,5 \mathrm{~mm}$, pétala espatulada glabra na base, anel estaminal com glândulas lobadas. Ocorre no México, Suriname, Peru, Brasil nos estados do Amazonas, Pará, Acre, Mato Grosso, geralmente habitando áreas pantanosas.

Espécimes examinados: MÉXICO. Chiapas: Novo Chihuahua a $70 \mathrm{~km} \mathrm{~S}$. de Boca Lacantum, Ocosingo, 23.VI.1986, E. Martinez 18978 (MEXU, RB); SURINAME. Brokopondo, J. van Donselaar 2891 (Parátipo U!); PERU.- Maynas: Rio Nnay bellow Bellavista, trail to Picuruyacu, 27.V.1972, S. MacDaniel 16059 (RB); BRASIL. Acre: Mâncio Lima, 70-80S e 720-730W., 24.X.1984, C.A. Cid Ferreira et al. s.n. (CEN); Pará: Gurupa, estrada do Rio Pucuruí, 18.VIII.1954, J.M.Pires \& N.T. Silva 4734 (Parátipo IAN!; IPEAN!); Gurupa, 28.VIII.1919, A. Ducke s.n. (RB14448).

3.4. Trigonia cipoensis Fromm \& Santos, Bradea 3(20):145. 1981.

Tipo: BRASIL. Minas Gerais: Serra do Cipó, 16.III.1964, E. Pereira 8908 (Holótipo HB!, Isótipo RB!).

Cápsula trilocular, trivalvar, deiscência concomitante nas duas extremidades, lanceolada, base aguda ou obtusa, ápice agudo, às vezes, apiculado, coriácea, castanho-amarelada, 2,5$4 \times 0,8-1 \mathrm{~cm}$; epicarpo verrucoso-tomentoso a glabrescente na face externa, glabro e reticulado na face interna; endocarpo livre, castanho, coriáceo, ápice inteiro, pubescente, castanho na face interna; parede lateral, castanha, coriácea, lisa; replum pendente, castanho, funículos 2-9; valva navicular, dorso em seção transversal agudo, abertura $0,3-0,8 \mathrm{~cm}$; sementes $2-9$ por valvas, orbiculares, tricomas $0,6-0,8 \mathrm{~cm}$ compr., enovelados, castanho-amarelados.

Subarbusto ereto com cerca de $50 \mathrm{~cm}$ de altura, folhas ovadas, obovadas, elípticas ou oblongo-elíticas, coriáceas, rígidas e alvas na face abaxial. Endêmica no Brasil nos estados do Ceará, Bahia e Minas Gerais onde é vulgarmente denominada cipó prata. Habita campos rupestres em altitudes superiores a $800 \mathrm{~ms} . \mathrm{m}$.

Espécimes selecionados: BRASIL. Bahia: Abaira, 13018'S 41053'W, 1400 ms.m., 29.IV.1994, W. Ganev 3182 (HUEFS, RB); Jacobina, Torre Nova, 01.VIII.2001. E.F. Guimarães 1714 et al. (RB); Mucugê, 05.VIII.2001, E.F. Guimarães 1732 \& M.C.M. Marques (RB); Rio de Contas, $1 \mathrm{~km}, 1000$ ms.m., 5.VIII.2001, E. F. Guimarães 1741 \& M. C. Marques (RB); Arapiranga, 5.VIII.2001. E.F. Guimarães 1742 \& M.C.M. Marques (RB); Minas Gerais: Santana do Riacho, Conceição do Mato Dentro, 1350 ms.m, 12.V.1987, R. Andreata 776 et al. (RB); Rio Pardo de Minas, $30 \mathrm{~km}$ de Mato Verde, 24.X.1979, E. Tenório \& L. C. Freitas 2454 (SPF).

3.5. Trigonia eriosperma (Lam.) Fromm \& Santos, Bol. Mus. Nac. Rio de Janeiro. 41:3. 1971. Tipo: BRASIL. Rio de Janeiro: s.d., P. Commerson s.n. (Holótipo P!). Fig. 2 I - o.

Cápsula trilocular, trivalvar, deiscência do ápice para a base, obovada, base aguda, dorso em seção transversal arredondado, ápice arredondado, coriácea, cinéreo-esverdeada, 1-1,3 x $0,6-0,8 \mathrm{~cm}$; epicarpo pubescente a glabrescente, reticulado-lenticelado na face externa, glabro-reticulado na face interna; endocarpo aderente, castanho-claro, coriáceo, ápice bífido, glabro na face interna, parede lateral castanho-clara, coriácea, lisa; replum ereto, aderente, funículos 4-5; valva navicular, dorso em seção transversal arredondado, abertura 0,1-0,2 cm; sementes 4-5 por valva, elípticas, tricomas $1,4-1,6 \mathrm{~cm}$ compr., enovelados, castanhos. Fig. 2, I-o.

Este táxon é caracterizado quando adulto pelas folhas concolores, quando jovens com tricomas alvos na face abaxial; com inflorescências duplo-racemo, cujas flores apresentam giba glabra externamente e anel estaminal com quatro estaminódios provido de duas glândulas apiculadas. Cresce na México, Guatemala, Colômbia, Brasil, nos estados do Pará, Rondônia, Ceará, Bahia, Minas Gerais, Espírito Santo, Rio de Janeiro e São Paulo. Ocorre em diferentes ecossistemas: floresta amazônica, floresta ombrófila densa, em restingas e em áreas perturbadas.

Espécimes selecionados: MÉXICO. Chiapas, 29.II.1948, E. Matuda 17630 (MEXU); COLÔMBIA. Estação de Primatas, $9^{\circ} 30^{\prime} \mathrm{N}, 75^{\circ} 48^{\prime} \mathrm{W}$, alt. 300m, 25. X.1989, A. Gentry \& H. Cuadrons 68186 (CEN, MO); BRASIL. Pará: Breu Branco, Rio Tocantins, 10.V.1978, M.G. Silva \& R. Bahia 3504 (INPA, MG, NY, RB); Bahia: Lençóis, 12030' 
46"S, 41021' 80"O, 28.VI.95, M.L. Guedes et al. 3844 (CEPEC); Minas Gerais: Coronel, Murta, V.1997, E. Tameirão Neto 2509 (BHCB, RB); Viçosa, 28.III.1930, Y.Mexia 4527 (F); Espírito Santo: Linhares, Rio Doce, Córrego Durão, 20.IX.1930, J.G. Kuhlmann 420 (VEN); Sta. Teresa, Reserva Biológica Augusto Ruschi, 3.X.2002, R.R. Vervolet 1129 et al. (MBML, RB); Rio de Janeiro: Búzios, 19.XI.1996, P.R. Farág 254 et al. (RB); Niterói, Itaipú, 27.V.1969, D. Sucre \& T.C. Plowmann 5129 (RB); Itaipuaçu, Falso Pão de Açúcar (22058'S, 4301' W), 14.I.1982, L.R. Landrum 4143 (CEN); Itaipuaçu, Pico Alto Mourão, 26.VIII.1981, R. Andreata 76 et al. (CEN, RB, RUSU); Paraíba do Sul, 22011'29,8', 43024'46"W, 2.VIII.2006, R. Marquete 3781 et al. (RB); Município do Rio de Janeiro: Guaratiba, 3.IX.1975, J. Miguel 43 (RB); Grumari, estrada de, 4.VII.1978, J. Miguel 63 (GUA, HB, INPA, R, RB); Ilha Furtada, Baia de Sepetiba, 25.VIII.1968, D. Sucre 3607 (RB); Jardim Botânico, encosta, 21.VI.1994, $R$. Marquete 1851 \& O. Marquete (F, RB); Sta. Ma. Madalena, Pedra Dubois, 16.III.1955, E. Pereira 1246 (CEN, RB); São Paulo: s.l. 1854, G.A. Lindberg $748(\mathrm{~S})$.

3.6. Trigonia fasciculata Griseb., Linnaea 22:29. 1849. Tipo: BRASIL. Bahia: ad montes, Serra Açurua, 1838, M. Blanchet 2921 (Holótipo G!, Isótipo BR!).

Cápsula trivalvar, trilocular, deiscência concomitante nas duas extremidades, lanceolada ou elíptica, base obtusa, ápice agudo, coriácea, castanha, 2,5-6 x 0,8-1,6 cm; epicarpo rufo-viloso, estriado-verrucoso na face externa, glabro, reticulado na interna; endocarpo livre, castanho, coriáceo, ápice inteiro, alvo- viloso na face interna; parede lateral, castanho-clara, papirácea, ondulada; replum pendente, castanho, funículos 8-10; valva navicular, dorso em seção transversal agudo, abertura de $0,2-1,0 \mathrm{~cm}$; sementes $8-10$ por valva, elípticas ou arredondadas, tricomas 0,30,5 cm compr., enovelados, castanhos.

Lianas com ramos não vigorosos com as foIhas fasciculadas, papiráceas ou cartáceas, alvas no dorso. Ocorre no Panamá, Brasil nos estados de Pernambuco, Bahia e Minas Gerais, geralmente em mata ciliar.

Espécimes examinados: PANAMÁ. Darien: Rio Areti, 7.XI.1967, J. Ducke \& N. Nickerson 14914 (MO); BRASIL. Pernambuco: Buique, Catimbaú, 8037" lat., 37010', alt. 790m , 18.V.2004, M.F. Sales 425 (CEN, PEUFR); Bahia: $16 \mathrm{Km} \mathrm{N} \mathrm{W}$ of Lagoinha, 5.III.1974, R.M. 16811(RB); Chapada Diamantina, Ibicoara, estrada Jussiape, Capão da Volta, $13^{\circ} 26^{\prime} 46^{\prime \prime} \mathrm{S}, 41^{\circ} 30^{\prime} 40^{\prime \prime} \mathrm{W}, 1284 \mathrm{~ms} . \mathrm{m} .$, 25.IX.2005, M.G. Bovini 2510 et al. (RB); Jaguaquara, 23.1.1965, Furlan, A. 708 \& Castellanos 25.460 (RB); Mucugê, 1200 ms.m, 27.III.1980, G. Martinelli 6694 et al. (RB); Rio de Contas, caminho para Arapiranga, 1000 ms.m., 5.VIII.2001, E.F. Guimarães 1743 \& M.C.M. Marques (RB); Minas Gerais: Lagoa Santa, Lagoinha, 5,5km SW de Delfino, 5.III.1974, M. Harley 16811 (HB, RB); Serra do Cipó, entre 132Km e Palácio, 4.XII.1949, A.P. Duarte 2040 (RB).

3.7. Trigonia floccosa Rusby, Bull. New York Bot. Gard. 4:325. 1907. Tipo: BOLÍVIA. Yungas Coripati, s.d., A.M.Bang 2191 (Holótipo NY! foto $\mathrm{NY}$ !, Isótipo $\mathrm{E}, \mathrm{G})$.

Cápsula trivalvar, trilocular, deiscência concomitante nas duas extremidades, lanceolada, velutíneo-tomentosa, base obtusa ou subaguda, ápice agudo 5-6x1,2 cm; epicarpo fulvo-tomentoso; endocarpo aderente, glabro; parede lateral não vista; replum formando 6 cordões, funículos 8-10; sementes 8-10 por valva, tricomas ca. de $12 \mathrm{~mm}$ de compr., enovelados, amarelados.

As folhas são opostas com tricomas de tonalidade amarelada na face abaxial e as flores apresentam sépalas glandulosas na margem.

\section{Chave para as variedades de Trigonia Floccosa}

1. Cápsula 5 a $6 \mathrm{~cm}$ comp.; endocarpo glabro.

3.7a. T. floccosa var. floccosa

1 ' Cápsula $12 \mathrm{~cm}$ comp.; endocarpo alvo-tomentoso. 3.7b T. floccosa var. ouropretensis

3.7a.Trigonia floccosa Rusby var. floccosa Distribuição geográfica: Bolívia.

Espécimes examinado: BOLÍVIA. Santa Cruz: s.d., Rusby, 2596 (NY).

3.7b. Trigonia floccosa var. ouropretensis Miguel \& E.F. Guim., Daphne, 4 (1):5-7. 1994. Tipo: Brasil: Minas Gerais, Município de Mariana, estrada de Ouro Preto para Mariana, a $6 \mathrm{~km}$ da Escola de Farmácia de Ouro Preto, 27.V.1978, J.Fontela 1074 \& Badini (Holótipo RB!).

Cápsula lanceolada, fulvo-tomentosa, base obtusa ou subaguda, ápice agudo 7,5-10,5×1,52,5 cm, epicarpo denso reticulado, amarelo-to- mentoso; endocarpo aderente, alvo-tomentoso, inteiro no ápice; parede lateral castanho-clara; replum formando 6 cordões, funículos 8-10; valva navicular dorso em seção transversal agudo, abertura 0,5-1,0 cm; sementes 8-10 por valva, orbiculares, tricomas, ca.12 mm compr., enovelados, amarelados.

Espécie conhecida pelo nome popular de cipó seda que apresenta folhas com pilosidade castanho amarelada na face abaxial e flores com sépalas glandulosas na margem. Endêmica do Brasil nos estados de Bahia e Minas Gerais, onde é frequente em matas de canga (J. Badini in sched.). 
Espécimes examinados: BRASIL. Bahia: Abaíra, Água Limpa, morro do Cuscuzeiro, alt. $1400 \mathrm{~m}, 13^{\circ} 18^{`} \mathrm{~S} 41^{\circ} 53^{`} \mathrm{~W}, 29 . I V .1994, W$. Gomes 3182 (HUEFS, RB); Minas Gerais: Belo Horizonte, Jardim Botânico, 9.III.1937, M. Barreto 8302 (BHCB, F); Caeté, Serra da Piedade, 2.XI.1957, M. Magalhães 9786 (BHCB); Carangola, rio Carangola fazenda Sta. Clara, 16.V.1992, L.S. Leoni 1854 (GFJP); Sta. Rita do Sapucaí, 25.V.1994, M. Brandão 24137 (PAMG); Santana do Riacho, Conceição do Mato Dentro, 2.V.1986, R. Simão s.n. et al. (SPF42337, RB391477).

3.8. Trigonia hypoleuca Griseb., Linnaea 22:30. 1849. Tipo: GUIANA. Schomburgk 315 (Holótipo GOET; Isótipo K!);

Cápsula trivalvar, unilocular, deiscência concomitante nas duas extremidades, lanceolada, base atenuada, ápice acuminado, coriácea, castanha, 5-7×2-3 cm; epicarpo tomentoso, enervado, castanho na face externa, glabro na interna; endocarpo aderente, castanho-avermelhado, cartilaginoso, ápice inteiro, com tricomas alvos na face interna; parede lateral castanho-clara, cartilaginosa, lisa; replum pêndulo, pubescente, castanho, funículos 14-16; valva coriácea, ovada, dorso em seção transversal arredondado; sementes 14-16 por valva, elíptico-lanceoladas, achatadas, equinado-pubescentes, tricomas 0,07-0,12 cm compr., castanho-amarelados.

Espécie reconhecida pelas folhas com tricomas alvo amareladoss na face abaxial; anel estaminal com estaminódios, ovário unilocular e as sementes com tricomas equinados. Sua ocorrência está assinalada na Guiana, Brasil nos estados do Amazonas, Pará, Acre e Rondônia em capoeiras de terra firme ou em florestas.

Espécimes examinados: GUIANA: Potaro-Siparuni: Essequibo Karupukari crossing; island channels, $2-3 \mathrm{~km}$ SE of falls. $04^{\circ} 39^{\prime} \mathrm{N}, 58^{\circ} 39^{\prime} \mathrm{W}$. Elev. 60m., 20.IV.1992, B. Hoffman 1355 (G); BRASIL. Acre: Mâncio Lima, estrada para Barão entre os $\mathrm{Km} 30$ e 52, $7^{\circ} 8^{\prime} \mathrm{S}-72^{\circ} 73^{\prime} \mathrm{W}$, 24.X. 1984, C.A. Cid Ferreira et al. 5225 (NY, MG); Amazonas: Manicoré, 07050'S, 6215'W, 15.IV.1985, C.A. Cid Ferreira 5553 (CEN).

3.9. Trigonia killipii J. F. Macbr., Field Mus. Nat. Hist., Bot. Ser. V.13, part. 3 (3):295.1950. Tipo: PERU. Junin: la Merced, s.d., Macbride 5513 (Holótipo F!, Isótipo G).

Cápsula trivalvar, trilocular, deiscência concomitante nas duas extremidades, lanceolada, base e ápice agudos, coriácea, castanha, 10-11x0,9-2,3 cm; epicarpo rufo-viloso, nervuras longitudinais salientes, verrucoso na face externa, glabro, liso na face interna; endocarpo aderente, castanho, coriáceo, ápice inteiro, alvo-velutíneo; parede lateral castanha, coriácea, ondulada; replum pendente, castanho; funículos não vistos; valvas naviculares, dorso em seção transversal agudo, abertura 0,6-2,2 $\mathrm{cm}$; sementes orbiculares, apiculadas, número de sementes por valva não visto, tricomas 1,6$1,9 \mathrm{~cm}$ compr., eretos, castanho-amarelados.

Caracterizada pelas inflorescências em racemos cujas flores apresentam pedúnculos com ca. 0,5 $\mathrm{mm}$; pétalas espatuladas pilosas na base e as duas glândulas do anel estaminal providas de apículo longo. Ocorre no Peru, Brasil nos estados do Roraima, Amapá, Amazonas, Pará, Acre e Rondônia, habitando matas de igapó, em savanas do Amazonas, florestas de Terra firme em solos argilosos, em altitudes que alcançam $110 \mathrm{~ms} . \mathrm{m}$.

Espécimes selecionados: BRASIL. Pará: Marabá, Serra dos Carajás, N-4, 20.III. 1984, A.S.L. da Silva et al. 1941 (MG); Rondônia: Buritis, fazenda do José Vespal, 22.XI. 1996, L. Carlos et al. 1237 (MG); Guajará-Mirim, Chapada dos Pacaás Novos a $10 \mathrm{Km}$ da cidade, $10^{\circ}$ 43'S 65 15'W, 11.IV.1987, C.A. Cid Ferreira 8810 (INPA); Abunã, trecho entre o Km 12 e o Km 36, 01.II.1983, L. Carreira et al. 439 (IAN, INPA, MG); fronteira Brasil-Bolívia, 23.IV.1976, M.R. Cordeiro 829 (IAN, INPA); Guaporá, estrada Vilhena-Pimenta Bueno, a 500m do Posto Fiscal do município, 09.XI.1979.

3.10. Trigonia laevis Aubl., Hist. PI. Guiane. 1:390. 1775. Tipo: GUIANA FRANCESA. Cayenne: s.d, Aublet s.n (Holotipo BM, Isotipo F, P, W!).

Cápsula trilocular, trivalvar, deiscência do ápice para a base, obovado-eliptica, base aguda, ápice agudo-apiculado, coriácea, castanha, 2,5-3,0x0,8-1,0 cm; epicarpo alvo-pubescente, liso na face externa, glabro, reticulado na face interna; endocarpo aderente, castanho, coriáceo, ápice inteiro, glabro na face interna, parede lateral castanha, papirácea, com nervuras; funículos 6-9, valva navicular, dorso em seção transversal arredondado, abertura de $1-1,5 \mathrm{~mm}$; replum ereto; sementes 6-9 por valva, orbiculares, tricomas ca. 0,3 cm compr., enovelados, castanhos.

O táxon dispõe de folhas opostas com tricomas em ambas as faces; inflorescências em panículas; anel estaminal com 3 estaminódios e duas glândulas globosas, pilosas. Ocorre na Guiana, Brasil, nos estados do Amazonas, Rondônia, Espírito Santo e Rio de Janeiro. Freqüente em regiões de altitudes.

Espécimes examinados: GUIANA FRANCESA. Cayenne: Upper Demerara, 05019'N, 058038'W, 29.X.1982, A.L. Stoffers 112 et al. (F); Região, Mabura Hill, 5025'N, $58^{\circ} 40^{\prime}$ W, 20.XI.1986, J.J. Pipoly 8969 et al. (CEN, MO); Sablonneux, 5.II.1966, Oldeman 1979 (CEN); Plateau Kaieteur, 3.V.1944, B. Maguire \& D.B. Faughawe 23192 (NY, RB); BRASIL. Amazonas: Tapinhoé, V.1950, O. Machado s.n. (RB 14451); Rondônia: Costa Marques, $12^{\circ} 25^{\prime} \mathrm{S}, 6^{\circ} 14^{\prime} \mathrm{W}$, 
M. Nee 34553 (CEN); Jaru, Igarapé e arredores, ponto I, $10^{\circ} 10^{\prime} \mathrm{S}, 62^{\circ} 05^{\prime} \mathrm{W}, 03 . X .1986, \mathrm{~S}$. R. Neto et al. 502 (F); Espírito Santo: Sta. Teresa, 25.XI.1953, A.P. Duarte 4011 (CEN, RB); Rio de Janeiro: Petrópolis, Carangola, X.1949, D.C. Góes \& D. Constantino, 553 (CEN, RB).

3.11. Trigonia littoralis Miguel \& $E$. F.Guim., Bradea. 5 (8): 32. 197-201. 2000. Tipo: BRASIL. Rio de Janeiro: Carapebus, margem da estrada em direção à Faz. São Lázaro, 16.VII.1997, J.G. Silva 4064 et al. (Holótipo R!).

Cápsula trilocular, trivalvar, deiscência do ápice para a base, elíptica a lanceolada, base aguda, ápice agudo-apiculado, coriácea, castanha, 2,5-3,5 x 0,8-1,5 cm; epicarpo alvo pubescente, lenticelado na face externa, glabro, reticulado na face interna; endocarpo aderente, castanho-claro, coriáceo, ápice bífido, glabro na face interna, parede lateral castanho-clara, coriácea, lisa; replum, ereto, castanho-claro; funículos 4-6; valva navicular, dorso em seção transversal agudo ou levemente arredondado, 0,3-0,7 cm de abertura; sementes 4-6 por valva, elípticas, tricomas $1,1-1,2 \mathrm{~cm}$ compr., enovelados, castanhos.

Espécie que apresenta como características as estipulas partidas, folhas glandulosas na face adaxial e anel estaminal com três estaminódios providos de duas glândulas multilaciniadas. Endêmica da região Sudeste do Brasil, nos estados de Minas Gerais e Rio de Janeiro. Ocorre em floresta ombrófila densa ou em áreas perturbadas.

Espécimes examinados: BRASIL. Minas Gerais: Ibitipoca, Fazenda Pedra Negra, Morro de Itaoca, ca. 40m s.m, 23.III.2001, J.M.A.Braga 6649 (RB); Rio de Janeiro: Campos, mata da Baronesa, I.1946, A.J. Sampaio 8754 (R); Carapebus, estrada em direção à Faz. São Lázaro 27.XII.2001, J. Miguel \& M. Gadoni 477 (RB); Rio das Ostras, 14.III.2000, H.N. Braga 899 (RB).

3.12. Trigonia microcarpa Sagot ex Warm. in Mart., Fl. bras. 13(2):131. 1875. Tipo: GUIANA FRANCESA. Karouany: 1855, Sagot 36 (Holotipo P, Isotipo BR, F, GH, GOET, S!, W!).

Cápsula trilocular, trivalvar, deiscência do ápice para a base, obovada, triangular, dorso em seção transversal arredondado, base aguda, ápice arredondado, coriácea, castanha, 0,5-0,8 x 0,5-0,6 cm; epicarpo castanho, pubescente, reticulado-bulado na face externa, glabro-reticulado na face interna; endocarpo livre, castanho-claro, coriáceo, ápice bipartido, glabro na face interna; parede lateral castanho clara, coriácea, lisa; replum ereto, aderente; funículos 1-2; valva triangular, dorso em seção transversal agudo ou arredondado, 3-6 mm de abertura; sementes 1-2 por valva, elípticas, tricomas 1,5-2 cm compr, eretos, castanhos.

Caracterizada pelas folhas glabras não glandulosas; com inflorescências dispostas em tirsos; seu pequeno fruto cordiforme a identifica com fa- cilidade. Cresce na Venezuela, Guiana Francesa, Suriname, Peru, Bolívia, Brasil, nos estados do Amapá, Amazonas, Pará, Acre, Rondônia, Maranhão, Bahia, Tocantins e Mato Grosso. Presentes em capoeira ou floresta de terra firme.

Espécimes selecionados: VENEZUELA. Bolívar: rio Botonamo, 12.XII.1959, L.A. Bernardi 7968 (VEN); GUIANA. Mabura Hill: Oeste de Demeara, $5^{\circ} 20^{\prime} \mathrm{N}-58^{\circ} 40^{\prime} \mathrm{W}$, 06.VI. 1986, J.J. Pipoly 7600 (INPA, NY, US); GUIANA FRANCESA. Nickerie: área do Kabalebo Dam project, 13.XI.1976, N.M. Heyde \& J.C. Lindeman 54 (MG); BOLÍVIA. La Paz: 12 a 30.VII.1939, B.A. Krukoff 10956 (F, S); Santa Cruz, Velasco, 18.X.1994, R.Guillén \& R. Chore 2400 (F); PERU. Imaza, 05003'20"S, $78^{\circ} 20^{\prime} 23^{\prime \prime} \mathrm{W}, R$. Vasquez et al. 21160 (F, MO); BRASIL. Amazonas: Manaus, Estrada do Aleixo, 29.XII.1942, A. Ducke s.n. (CEN, RB47812); Mâncio Lima, 70-80S, 720-730 W, 24.X.1984, C.A.C. Ferreira et al. 5231 (CEN); Pará: Belterra, 24.VI. 1947, G.A. Black 47-932 (IAN); Rondônia: rodovia Alvorada-Costa Marques, 25.VI.1983, M.G. Silva 6442 (MG, RB); Mato Grosso: Aripuanã, BR-174, Projeto Juína, arredores do núcleo, 31.V.1979, M.G. Silva \& C. Rosário 4733 (MG); Bahia: Itiruçu, Rodovia-BA 250, 29.II.1988, L.A. Matos Silva et al. 2225 (CEPEC, RB); Lençóis, 11.VI.1981, S.A. Mori 14334 \& B.M. Boom (NY, RB); Maracás, BR 250, Fazenda dos Pássaros, 04.V.1979, S A. Mori 11777 \& T. S. dos Santos (CEPEC, INPA, RB).

3.13. Trigonia nivea Cambess., in A.St. Hil., Fl. Bras. Mer. 2:81. 1829. Tipo: BRASIL. Rio de Janeiro: In sylvus prope Sebastianopolin, lecta cum fructibus augusto, s.d., Saint Hilaire 226 (Holótipo MPU, foto do tipo IAN!). Fig. 2: $f-j$.

Cápsula trivalvar, trilocular, deiscência concomitante nas duas extremidades, oblongo-elíptica, elíptica; base e ápice arredondados ou agudos, coriácea, castanha; até $7 \mathrm{~cm}$ compr.; epicarpo com protuberâncias ou liso, rufo-viloso; endocarpo livre, glabro ou tomentoso na face interna; parede lateral castanha, papirácea; replum pendente, formando seis cordões; funículo 6-12; valva navicular, dorso em seção transversal arredondado ou anguloso; sementes 6-12 por valva, orbiculares, tricomas 0,8-1,2 cm compr., enovelados, castanhos.

Espécie conhecida vulgarmente como mufumbo, cipó de cabra, cipó de arco, cipó de paina, caracteriza-se por apresentar folhas discolores, com tricomas alvos ou acinzentados na face abaxial; brácteas, bractéolas e sépalas não papiloso-glandulares; 3-4 estaminódios. Frequente da Venezuela até o Paraguai, com ampla distribuição pelos estados brasileiros, habitando floresta ombrófila densa, cerrado, campos rupestres, geralmente em bordas de matas, clareiras, áreas em regeneração e ainda em mata ciliar, em altitudes que variam de 300 a $600 \mathrm{~ms} . \mathrm{m}$. 
1. Epicarpo com protuberâncias na face externa; valvas arredondadas no dorso....3.13b. T. nivea var. nivea 1'. Epicarpo sem protuberâncias, liso na face externa; valvas angulosas no dorso.

2. Folhas alvas na face abaxial, dorso da valva anguloso

3.13a. T. nivea var. candida 2' Folhas cinéreo-tomentosas na face abaxial, dorso da valva arredondado...3.13c. T. nivea var. pubescens

3.13a. Trigonia nivea var. candida (Warm.) Miguel, E.F. Guim. \& Lleras, Daphne, 3(4):7-10. 1993.

三 Trigonia candida Warm., Mart. Fl. bras. 13(2):139.1875. Tipo: Rio de Janeiro: Corcovado, Cova da Onça, 28.II.1868, A.F.M. Glaziou 2505 (C, CH, F, NY, Lectotipo R!; Isótipo RB!, US).

Cápsula lanceolada, às vezes, obovada, base e ápice agudos, coriácea, castanho-escura, 4-4,2x0,9-1,3 cm.; epicarpo sem protuberâncias, liso, na face externa, fulvo-tomentoso, não rugoso, estriado; endocarpo livre, castanho-claro, cartilaginoso, ápice inteiro, com tricomas curtos; parede lateral marfim, papirácea, sutilmente estriada, replum pendente; funículos 6-10; valva navicular, dorso em seção transversal agudo, abertura 0,2-0,4cm; sementes 6-10 por valva, orbiculares.

Distribuição geográfica: Brasil nos estados do Ceará, Paraíba, Bahia, Minas Gerais, Espírito Santo, Rio de Janeiro, São Paulo e Paraná.

Espécimes examinados: BRASIL. Paraíba: Caeté, Serra da Piedade, 2.XI.1957, M. MagaIhães 9786 (BHCB); Pitimbu, 22.VII.2001, R.M. Silva 1835 et al. (RB, SPF); Bahia: Vitória da Conquista, 10.VII.1964, E. Duarte \& A. CasteIhanos 304 (HB); Minas Gerais: Inter Minas et Caldas (ex herb Bras.), 23.III.1845, A.F. Regnel 225 (S); Espiríto Santo, 5.XI.1976, P. Occhioni 7945 (RFA); Rio de Janeiro: Paty do Alferes, Arcozelo, 11.IV.1995, J. Miguel 271 (RB); Paraty, Estrada da Fazenda Olaria-Paraty a 2,5km, entre 200-400 m s.m., 18.I.1994, J. Miguel 498 et al. (RB); São Paulo: Serra do Picu, 1880, A.F.M. Glaziou 10730 (G); Paraná: Lupionópolis, Mata São Pedro. 03.III.2006, J.L. Carneiro et al. 466 (FUEL, RB).

\subsection{3b. Trigonia nivea Cambess. var. nivea}

Cápsula elíptica, base e ápice arredondados, coriácea, castanha,dorso da valva anguloso, 4-7x1,3-1,5 cm; epicarpo rufo-viloso com protuberâncias na face externa, glabro, denso-reticulado na face interna; endocarpo livre, castanho-pubescente, coriáceo, ápice inteiro; parede lateral castanha, coriácea, ondulada; funículos 10-12; valva navicular, dorso em seção transversal arredondado, abertura 0,3-0,4 $\mathrm{cm}$; sementes 10-12 por valva, orbiculares. Fig. $2 f-j$.

Distribuição geográfica: Venezuela, Guiana, Paraguai, Brasil nos estados do Pará, Maranhão, Piauí, Ceará, Paraíba, Pernambuco, Sergipe, Bahia, Minas Gerais, Espírito Santo, Rio de Janeiro, São Paulo e Paraná.
Espécimes selecionados: BRASIL. Paraíba: João Pessoa, Campus da UFPB, 09.V.1979, M.J. Agra 140 (JPB, RB); Pernambuco: Betânia, Serra dos Arrombados, 24.V.1971; E.P. Heringer 878 (IPA, RB); Sergipe: Sta. Luzia do Itanhi, $11^{\circ} 15^{\prime} 30^{\prime \prime S}$, 37016'38'W, 15.VI.1994, L.A. Mattos Silva et al. 3018 (CEN); Bahia: Ilhéus, Reserva Biológica do Mico-Leão $15^{\circ} 09^{\prime} S$, 39०0,5'W, S.C. de Sant'Ana et al 539 (CEN); Minas Gerais, Marlieria, Parque estadual do Rio Doce, 25.X.2006, M.G. Bovini 2627 \& al. (RB); Espírito Santo: Sta. Tereza, Estação Biológica de Santa Lúcia, 19.IX.1988, H.Q. Boudet Fernandes 2529 et al. (MBML, RB); Rio de Janeiro: Morro Dois Irmãos, 15.II.2003, J. Miguel 475 \& E.F. Guimarães (RB); Angra dos Reis, 11.IV.1995, J. Miguel 365 \& E.F. Guimarães (RB); Ilha Grande, Represa, 27.IV.1963, M.C. Viana 118 (GUA, RB); Teresópolis, Estrada, próximo à Parada Modelo, 1.II.1975, P. Occhioni 7003 (RFA); 22026'53"S x 42058'20"W, 26.VIII.2002, R. Marquete 3388 et al. (RB).

3.13c. Trigonia nivea var. pubescens (Cambess.) Lleras, Flora Neotrop. Monogr. 19:52. 1978.

$\equiv$ Trigonia pubescens Cambess., A.St. Hil. Fl. Bras. Mer. 2:114. 1829. Tipo: Nascitur in sylvis prope praedium Itajuru de São Miguel de Mato Dentro in província de Minas Gerais, s.d., Saint Hillaire 2205 (Holótipo MPU, Isótipo P!).

Cápsula elíptico-oblonga, base e ápice agudos, coriácea, castanho-escura, dorso arredondado, 2-4 x 0,7 - 1,4 cm; epicarpo cinéreo-tomentoso, verrucoso na face externa, glabro, profuso-reticulado na face interna; endocarpo livre, castanho-claro, coriáceo, ápice inteiro, pubescente, tricomas castanho-amarelados na face interna; parede lateral, castanho-clara, papiráceo-ondulada, replum pendente, castanho-amarelado; funículos 6-10; valva navicular, dorso em seção transversal arredondado, 0,3-0,5 cm de abertura; sementes 6-10 por valva, orbiculares.

Comentários: variedade distinta pelas foIhas cinério tomentosas na face abaxial.

Distribuição geográfica: Venezuela, Brasil nos estados do Pará, Maranhão, Paraíba, Bahia, Minas Gerais, Espírito Santo, Rio de Janeiro, São Paulo, Paraná e Santa Catarina.

Espécimes examinados: Venezuela. Distrito Pedro Camejo: 60 36 $\mathrm{N}, 67^{\circ} 16^{`} \mathrm{~W}$, 23.II.1978, G. Davidse 15.590 (MO); Brasil. Paraíba: João Pessoa, 28.VII.2001, J. Miguel s.n. et al. (RB433642); Bahia: Canudos, Toca Velha, 
ca. $10 \mathrm{~km}$ ao Sul, 11.VIII.1985, L.C. Gonzaga 36 (CEN, RB); Minas Gerais: Diamantina, 10.VII.1958, A.C. Brade 13889 (RB); Lagoa Santa, Fazenda do Cipó, 18.VI.1946, A.P. Duarte 8142 (RB); Espírito Santo: Penha, 1.X.85, W. Boone 799 (MBML, RB); Rio de Janeiro: Corcovado, 1886, A.F.M. Glaziou 8670 (G); Santa Catarina: Brusque, mata de Malucher, 27006'S, 48054'W, 40-50 ms.m, 23.II.1952, L.B. Smith 5795 (VEN).

3.14 Trigonia paniculata Warm., Mart. FI. bras. 13(2):132. 1875. Tipo: BRASIL. Rio de Janeiro: Laranjeira, s.d, Glaziou 2938 (Lectotipo $\mathrm{C}$ !, Isotipo $\mathrm{BM}, \mathrm{BR}, \mathrm{P}$ ).

Cápsula trilocular, trivalvar, deiscência do ápice para a base, obovada, elíptica, dorso em seção transversal anguloso, base atenuada, ápice truncado-apiculado, coriácea, castanho-esverdeada, dorso em seção transversal agudo 1,5-2 x 0,8-I,3 $\mathrm{cm}$; epicarpo tomentoso (flavo-pubescente), reticulado-verrucoso na face externa, glabro, alvo-reticulado na face interna; endocarpo aderente, castanho-claro, coriáceo, ápice bífido, glabro na face interna, parede lateral castanho-clara, coriácea, reticulada; replum ereto, castanho-claro; funículos 2-3; valva navicular, dorso em seção transversal agudo, abertura $0,1-0,3 \mathrm{~cm}$; sementes 2-3 por valva, orbiculares, tricomas $0,5-0,8$ $\mathrm{cm}$ de compr., enovelados, castanhos.

Espécie com estipula bífida e folha tomentosa na face abaxial destacando-se nesta face uma linha marginal alva. Endêmica do Brasil, nos estados da Bahia, Minas Gerais, Espírito Santo, Rio de Janeiro e São Paulo. Frequente em floresta ombrófila densa.

Espécimes selecionados: BRASIL. Bahia: Lençóis, mata das Toalhas, $12^{\circ} 34^{\prime} \mathrm{S}, 41^{\circ} 23^{\prime} \mathrm{W}$, alt.450ms.m, 26.III.2000, L.S. Funch 1132 \& R. Funch (HUEFS); Minas Gerais: Caratinga, Estação Biológica, 21.IV.1984, I.K. Matão, M.A. Lopes 345 \& P.M. Andrade (BHCB); Viçosa, 20.V.1978, J.P. Fontella, 1006 \& R. Vidal (HRB, NY, PAMG, R, RB); Espírito Santo: Santa Teresa, Pedra da Onça; ca. de 800 ms.m, 10.I.2001, J. Miguel \& V. Demuner 466 (MBML, RB); Rio de Janeiro: Petrópolis, Carangola, IX.1948, C. Goes \& D. Constantino 509 (RB); São Paulo: Mogi das Cruzes, 20.IV.1989, C.A.W. Schwacke 6544 (RB).

3.15. Trigonia prancei Lleras, Flora Neotropica Monogr. 19:33, fig. 12. 1978. Tipo: PERU. Loreto: Rio Javari, Angano Garrison, 04.VIII.1973, Lleras, Steward et al. P17115 (Holótipo INPA!; foto NY!; Isótipo COL, F, K, MG, MO, NY, US).

Cápsula trivalvar, trilocular, deiscência concomitante nas duas extremidades, lanceolada, base aguda, ápice agudo, às vezes, uncinado, papirácea, castanha, Cápsulas 9,0-9,5×2-2,4 $\mathrm{cm}$; epicarpo, castanho, viloso, com nervuras na face externa, glabro, reticulado na interna; endocarpo aderente, castanho, papiráceo, ápice inteiro, glabro a pubescente na face interna; parede lateral, castanha, papirácea, nervada, replum pêndulo, glabro, castanho; funículos 18-20; valva navicular, dorso em seção transversal agudo, 0,3-0,7 cm; sementes $18-20$ por valva, subglobosas, tricomas $0,7-0,8 \mathrm{~cm}$ compr., enovelados, castanhos.

Este táxon caracteriza-se por ser liana com inflorescências dispostas em tirsos e flores com pedúnculo até $2 \mathrm{~mm}$ de comprimento. Ocorre no Peru e Brasil no estado do Acre. Habita terras baixas, não inundadas, abertas, perturbadas em margens de florestas (fide Lheras, 1978).

Espécimes examinados: PERU. Nauta, rio Marañon, 73030'W, 4030'S, 11.X.1980, A. Gentry et al. 29958 (CEN); BRASIL - Acre: Cruzeiro do Sul, Rio Juruá, $7038^{`} \mathrm{~S}, 72^{\circ}$ 36 `W; Município Mâncio Lima, 70-80, 72-73 `W, 24.X.1984, C.A.Cid Ferreira et al. 5225 (MG).

3.16. Trigonia reticulata Lleras, Flora Neotropica Monogr. 19:41. 1978. Tipo: Guyana. Mazaruni river basin, Kako,24.IX.1960, Tillett \& Tillett 45524 (Holótipo NY!; Isótipo F, GH, P, US).

"Fruto jovem oblongo, denso viloso, tomentoso" Lleras (1978).

Espécie que se caracteriza por ser lianas, com brácteas e sépalas papiloso-glandulares. Ocorre na Venezuela, Guiana, habitando margens de florestas ou em áreas abertas ao longo das estradas ou rios. (fide Lheras, 1978).

Espécimes examinados: VENEZUELA. Estado Bolívar: vicinity de $150 \mathrm{Km}$ sul de El Dourado, Nordeste de Luepa, altitude 800-1200ms.m, 6-11.III.1962, J.A. Steyermark \& L. Aristeguieta 77 (U, V, fide Lleras, 1978).

3.17. Trigonia rotundifolia Lleras, Flora Neotrop. Monogr. 19:33, fig. 12, 1978. Tipo: BRASIL. Rio de Janeiro: Mangaratiba, 14.II.1968, L.B. Smith \& McWilliams 15441 (Holótipo MO; Isótipo US!).

Cápsula trivalvar, trilocular, deiscência concomitante nas duas extremidades, lanceolada a falcado-lanceolada, base arredondada, ápice apiculado, papirácea a coriácea, castanha, 6,88,7×1,7-2,3 cm.; epicarpo rufo-híspido, com reticulo saliente na face externa, glabro, reticulado na face interna; endocarpo aderente, castanho, papiráceo rígido, ápice bífido, velutíneo a pubescente, alvo-amarelado na face interna; parede lateral castanho-clara, papirácea, ondulada; replum pêndulo, pubescente, castanho-claro; funículos 8 a 10; valva navicular, dorso em seção transversal agudo, abertura $0,1-1,5$ $\mathrm{cm}$; sementes 8-10 por valva, arredondadas, envolvidas por tricomas $1,2-1,5 \mathrm{~cm}$ compr., eretos, castanhos.

Popularmente conhecida como cipó-caboclo; tem folhas arredondadas ou subarredondadas, alvas na face adaxial e ovário tetralocular. Endêmica da região Sudeste do Brasil nos es- 
tados do Rio de Janeiro e São Paulo; habita a mata ciliar da floresta ombrófila densa.

Espécimes examinados: BRASIL. Rio de Janeiro: Paraty, Morro do Coriscão, 29.XI.1994, J. Miguel 233 et al (RB!, RUSU!). APA Cairuçu, Rio Corisco, 260 ms.m., 28.XI.1994, J. Miguel 233, L.C. Giordano \& M.G. Bovini (RB, US); Morro Cuscuzeiro, 670 ms.m., 28.III.1995, J. Miguel 234 et al. (RB).

3.18. Trigonia rugosa Benth., Bot. Voy. Sulphur, part. 4, 74. 1844. Tipo: AMÉRICA CENTRAL. s.I., s.d, Sinclair s.n. (Holótipo K!).

Cápsula trilocular, trivalvar, deiscência do ápice para a base, elíptica a oblongo-elíptica, base obtusa, ápice agudo apiculado, coriácea, castanha, 2-3,5 x 1-2 cm; epicarpo pubescente, alvo-amarelado, reticulado na face externa, glabro-reticulado na face interna; endocarpo aderente, castanho-claro, coriáceo, ápice bífido, pubescente, tricomas castanhos na face interna, parede lateral castanho-clara, coriácea, reticulada; replum ereto, perceptível; funículos 10-12; valva navicular, dorso em seção transversal arredondado, $0,1-0,4 \mathrm{~cm}$ de abertura; sementes 10-12 por valva, obovadas, sulcadas em uma das faces, tricomas 1-1,2 cm compr., enovelados, castanhos.

Trata-se de um arbusto com folhas membranáceas, castanho-amareladas tomentosas na face abaxial e flores em panícula com as glândulas do anel estaminal lobadas. Ocorre no México, Nicarágua, Costa Rica, Colômbia, Venezuela, Brasil, nos estados de Rondônia e Bahia. Habita floresta tropical e subtropical.

Espécimes examinados: MÉXICO, 14.V.1947, E. Matuda 16548 fl. (MEXU); NICARÁGUA. Esteli: Municipio de San Juan de Limay, $2 \mathrm{~km}$ de la "Hda. La Grecia; 13012'N, 86036'W, elev.280-300ms.m, 2.IX.1980, P. Moreno 2028 (CEN); COSTA RICA. Guanacaste: $10^{\circ} 44^{\prime} \mathrm{N}-85^{\circ} 31^{\prime} \mathrm{W}$, 25.I.1983, G. Davidse 23297 et al. (INPA, MO); VENEZUELA. Zulia: Colón, arredores de Casigua-Palmira, 11.XII.1979, G.S. Bunting 8349 \& M.Fucci (VEN); COLÔMBIA. II.1936, A. Dugand 921 (F); BRASIL. Rondônia: Rio São Miguel, 20.VI.1952, G.A. Black \& E. Cordeiro 52-15228 (IAN); BAHIA. Jequié, Fazenda Progresso, 26.VII.1964, C.M. Marques 242 (CEPEC).

3.19. Trigonia rytidocarpa Casar., Nov. Stirp. Bras. Dec. 76. 1845. Tipo: BRASIL. Rio de Janeiro, 1839-40, Casareto 1956 fl, fr (Holótipo TO, Isotipo G!).

Cápsula trilocular, trivalvar, deiscência do ápice para a base, elíptica, base arredondada, ápice agudo apiculado, coriácea, castanha, 1,5-3 x l-1,5 cm; epicarpo fulvo-tomentoso, verrucoso, com saliências na face externa, glabro, espesso-reticulado com pontuações castanhas na face interna; endocarpo aderente, castanho com estrias ferrugíneas, coriáceo, ápice bífido, viloso, com tricomas alvos na face inter- na; parede lateral castanha, com estrias ferrugíneas, coriácea; replum ereto; funículos 5-7; valva navicular, dorso em seção transversal arredondado; abertura 0,2-0,6 cm; sementes 5-7 por valva, oblongas, apiculadas, tricomas 0,2$0,3 \mathrm{~cm}$ compr., enovelados, castanhos.

1. Espécie que se apresenta como arbusto escandente, com folhas opostas, concolores, as inflorescências dispostas em panículas com flores que apresentam o anel estaminal com 3-4 estaminódios. Endêmica no Brasil, nos estados da Bahia, Minas Gerais, Espírito Santo, Rio de Janeiro São Paulo. Ocorre na floresta ombrófila densa.

Espécimes examinados: BRASIL. Minas Gerais: s.I, 1885, A.F.M. Glaziou 19688 (G); Espírito Santo: Santa Teresa, Pedra Alegre, 10.I.2001, J. Miguel 464 \& V. Demuner (MBML); Rio de Janeiro, Jacarepaguá, Floresta da Covanca, 29.IV.1947, J.N. Vieira s.n. (RB60058); Nova Iguaçu, Serra Velha, 800 ms.m., 25.IV.2002, G.V. Somner 995 et al. (RB, RBR).

3.20. Trigonia sericea Kunth in Humb., Bonpl. Nov. gen. \& sp. pl. 5(4): 141-142. 1821. Tipo: COLÔMBIA. Andes de Quindie: s.d. Humboldt 1859, fl (Holótipo P!, Isótipo P!).

Cápsula trivalvar, trilocular, deiscência concomitante nas duas extremidades, lanceolada, oblongo-lanceolada, base obtusa, ápice agudo-acuminado, coriácea, castanha, 6,5-6,8 8x1,5$-1,8 \mathrm{~cm}$; epicarpo rufo-tomentoso externo e internamente, nervuras salientes; endocarpo aderente, castanho, coriáceo, ápice inteiro, pubescente, amarelado na face interna, parede lateral castanha, coriácea, lisa; replum ereto, castanho; funículos 8-11; valva navicular, dorso em seção transversal arredondado a sutilmente agudo, aberturas $0,1-0,5 \mathrm{~cm}$; sementes $8-11$ por valva, elípticas, tricomas $1-1,5 \mathrm{~cm}$ compr., enovelados, castanhos.

Espécie com folhas opostas, glandulosas na face adaxial, lanoso amareladas na abaxial; as flores apresentam as sépalas desprovidas de glândulas e o anel estaminal dispõe de glândulas laciniadas. Ocorre na Colômbia, Venezuela, Peru, Brasil nos estados do Amazonas, Acre e Rondônia, habitando florestas periodicamente inundadas.

Espécimes examinados: VENEZUELA. Bolívar: Chimatá Massif, 25.III.1953, J.A. Steyermark 74649 (F); PERU - Iquitos: rio Nanay near Sta. Clara, on edge of river, ca. 95 ms.m., 9.I.1977, M.S. Macdaniel 21103 \& M. Rimachi (RB); Loreto: Maynas, alt. 120ms.m, 11.I.1976, A. Gentry et al. 15849 (CEN); Huánuco, Pachitea, Bosque Nacional de Iparia, 1.XI.1967, J. Schunke 2299 (F); BRASIL. Acre: $55 \mathrm{~km}$ da Estrada para Brasiléia, 3.X.1980, S.R. Lowrie 354 et al. (INPA, NY, RB); Rondônia: Guaporé, 9.XI.1979, M.G. Vieira 1054 et al. (INPA, RB).

3.21. Trigonia simplex Warm., Mart. Fl. bras. 13(2):125. 1875. Tipo: BRASIL. Minas 
Gerais: Lagoa Santa, 13.XI.1863, E. Warming 596. (Holótipo C!).

Cápsula trilocular, trivalvar, deiscência do ápice para a base, elíptica, base atenuada, ápice agudo apiculado, coriácea, castanha, 1,8-3 $\times 0,8-1 \mathrm{~cm}$; epicarpo pubescente a glabrescente, profuso-lenticelado na face externa, glabro, cinéreo-reticulado na face interna; endocarpo livre, castanho-claro, coriáceo, ápice bífido, glabro na face interna; parede lateral castanho-clara, coriácea, lisa; replum ereto, castanho-claro; funículos 4-6; valva navicular, dorso em seção transversal arredondado ou agudo; abertura 0,2-0,4 cm; sementes 4-6 por valva, elípticas, tricomas ca. $0,8 \mathrm{~cm}$ compr., enovelados, castanhos.

Espécie caracterizada por ser um arbusto escandente de folhas opostas com inflorescências em racemos simples, cujas flores apresentam anel estaminal com 3-4 estaminódios. Endêmica do Brasil, nos estados de Minas Gerais, Espírito Santo, Rio de Janeiro e São Paulo. Habita floresta ombrófila densa.

Espécimes examinados: BRASIL. Minas Gerais: Barroso, Mata do Baú, 17.IX.2001, L.C. Assis 245 \& M.K. Ladeira (CESJ, RB); Viçosa, estrada de Porto Firme, 20.V.1978, J.P. Fontella 1007 et al. (CEN, RB, VIC); Espírito Santo: Alto Tabocas, 800 m s.m., 06.IV.1999, L. Kollmann 2408 et al. (MBML, RB); Santa Teresa, Santa Lúcia, 9.IV.1984, W. Pizziolo 18 (MBML, RB); Rio de Janeiro: Magé, Cachoeira de Macacú, Estação Estadual de Paraíso, 29.IV.1992, M.V.Peron 134 et al. (RB); São Paulo: 1.XII.1874, H. Mosén 18 (S).

3.22. Trigonia spruceana Benth. ex Warm., Mart. Fl. bras. 13(2):130, 1875. Tipo: BRASIL. Amazonas. Prope Barra [Manaus], Prov. Rio Negro, V.1851, Spruce 1501 (Isótipo foto NY!).

Cápsula trivalvar, trilocular, deiscência concomitante nas duas extremidades, lanceolada, base e ápice agudos, subcoriácea, castanha, 4-5x2-2,5 cm; epicarpo fulvo-denso-tomentoso, com nervuras salientes na face externa, glabro, reticulado na face interna; endocarpo aderente, castanho claro, subcoriáceo, ápice inteiro, pubescente, amarelado na face interna, parede lateral castanho-clara, papirácea, liso-ondulado-reticulada; replum flexível, castanho-claro; funículos 8-9; valva navicular, dorso em seção transversal agudo, abertura 1,5-2 cm; sementes 8-9 por valva, orbiculares, trico- mas $0,3-0,4 \mathrm{~cm}$ compr., eretos, castanhos.

Trata-se de liana com folhas opostas que apresentam brácteas, bractéolas e sépalas não papiloso-glandulares; flores com o anel estaminal com glândula trilobada, desprovido de estaminódios; sementes equinado pubescentes. Ocorre na Venezuela e no Brasil nos estados de Roraima, Amazonas e Pará e desenvolve-se em margens de rios ou florestas periodicamente inundadas.

Espécimes selecionados: VENEZUELA. Capihuara: Casiquiare, alt. 118ms.m., 12.III.1942, L. Williams 14770 (F); BRASIL. Roraima: Boa Vista, Rio Araça, 24.X.1952, R.L.Fróes \& G. Addison 29067 (IAN); Amazonas: São Carlos, Rio Negro, $1^{\circ} 55^{\prime} \mathrm{N} 67^{\circ} 5^{\prime} \mathrm{W}, 3 . X \mathrm{XI} .1977, R$. Liesner 4157 (INPA, MO); Ponta do pagodão, ca. 02052'S, 060029'W, Igapó, 3.VIII.1991, S. Mori \& C. Gracie 21905 (CEN); Igarapé Tupé, 24.IV.1973, M.F. Silva 1060 et al. (RB); rio Pasimoni, 1053'-1027' N, 66035'-66032'W; elev. 80ms.m., 23-25.VII.1984, S. Mori \& C. Gracie 22450 (CEN); Pará: Oriximiná, rio Trombetas, margem esquerda, 07.VII.1980, C.A. Cid Ferreira et al. 1328 (INPA).

3.23. Trigonia villosa Aubl., Hist. PI. Guiane $1: 388$, t.149. 1775 . Tipo: GUIANA FRANCESA. Cayenne, 1775, Aublet s.n. (Lectotipo BM!).

Cápsula trivalvar, trilocular, deiscência concomitante nas duas extremidades, lanceolada, base atenuada, aguda ou obtusa; epicarpo com protuberâncias ou reticulado, com nervuras na face externa, velutíneo a estrigoso, castanho a amarelado; mesocarpo castanho, reticulado, papiráceo; endocarpo livre ou aderente, castanho claro, córneo, agudo, inteiro no ápice; replum formando seis cordões cilíndricos, castanho-claro; funículos 2 - 12; valva navicular, dorso em seção transversal agudo a arredondado, abertura $0,3-2 \mathrm{~cm}$; sementes $2-12$ por valva, orbiculares, tricomas de $0,2-1,0 \mathrm{~cm}$ compr., enovelados a eretos, castanhos.

Caracterizada por ser um arbusto de foIhas opostas, desprovidas de glândulas na face adaxial, com tricomas castanho-amarelados na abaxial. As sépalas são desprovidas de glândulas na margem. Ocorre na Venezuela. Suriname e Guina Francesa e Brasil nos estados de Roraima, Amapá, Amazonas, Pará, Acre, Rondônia, Ceará e Rio de Janeiro, habitando áreas das florestas Amazônica e Atlântica nesta, não raro em restingas.

\section{Chave de identificação para AS Variedades de Trigonia Villosa}

1. Endocarpo livre

3.23c. Trigonia villosa var. villosa

$1^{\prime}$. Endocarpo aderente

2. Cápsula com base atenuada a aguda; parede lateral 2-3,2cm larg. 3.23a. Trigonia villosa var. duckei

2'. Cápsula com base obtusa; parede lateral 1-1,2cm larg.........3.23b. Trigonia villosa var. macrocarpa 
3.23a. Trigonia villosa var. duckei E.F. Guim. \& Miguel, Rodriguésia 32(54):41-47. 1980. Tipo: BRASIL. Amazonas: Manaus, 9-I1933, A. Ducke s.n. (Holótipo RB 23871!).

Cápsula lanceolada, base atenuada a aguda, ápice agudo-apiculado, coriácea, castanho-amarelado, 8-13×2-3,2 cm; epicarpo rufo-estrigoso, com nervuras na face externa, reticulado na interna; endocarpo aderente, marfim, papiráceo-rígido, ápice inteiro, alvo-viloso; parede lateral castanho-clara, papirácea, reticulada; replum pêndulo, marfim, funículos 10-12; valva navicular, dorso em seção transversal arredondado, presença de nervura longitudinal saliente, 0,3-1 $\mathrm{cm}$ de abertura; sementes 10-12 por valva, orbiculares, apiculadas, tricomas até $0,2 \mathrm{~cm}$ compr., enovelados, castanhos.

Distribuição geográfica: Brasil, nos estados do Amazonas e Amapá.

Espécimes examinados: BRASIL. Amazonas: Manaus, Igarapé do Passarinho, 18.IV.1955, J. Chagas, s.n (INPA, Parátipo RB197239!).

3.23b. Trigonia villosa var. macrocarpa (Benth.) Lleras, Flora Neotrop. Monogr. 19:57. 1978.

$\equiv$ Trigonia macrocarpa Benth., London Journ. Bot. 2:373. 1843. Tipo: GUIANA. Essequibo River, s.d., Schomburgk 54 fl,fr. (Holótipo K!).

Cápsula lanceolada, base obtusa, ápice agudo, coriácea, castanha, 6-13 x 1-1,2 cm; epicarpo lanado a viloso, com nervuras acentuadas na face externa, glabro, liso na interna; endocarpo aderente, castanho, coriáceo, ápice inteiro, alvo-pubescente na face interna; parede lateral castanho-escura, papirácea, reticulada; replum formando seis cordões; funículos 4 a 6; valva navicular, dorso em seção transversal agudo, abertura 0,3-0,7 cm; número de sementes por valva não visto 4 a 6 por valva, tricomas eretos, castanhos.

Na Venezuela é conhecida com o nome popular de bejuco-negrão.

Distribuição geográfica: Venezuela, Guiana, Brasil, nos estados de Roraima, Amapá, Pará e Acre.

Espécimes examinados: VENEZUELA. Estado Bolívar: entre 2 e $8 \mathrm{~km}$ Leste de Paragua, $6^{\circ} 50^{\prime} \mathrm{N}$, 25.VII.1978, R. Liesner \& A.C. Gonzalez 5629 (VEN); BRASIL. Roraima: Pacaraima, 13.V.1998, C.A. Cid Ferreira et al. 11593 (INPA); Amazonas: Manaus, igarapé do Passarinho, 18.IV.1955, J. Chagas s.n. (INPA 971, RB); Pará: Iaitiba, Serra

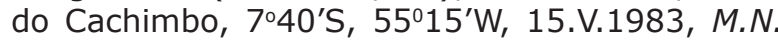
Silva 289-a (RB); Acre: Rio Branco, Caracarahy, XII.1912, J.G. Kuhlmann 60 (CEN, RB);

\subsection{3c. Trigonia villosa Aubl. var. villosa.}

Cápsula lanceolada, base e ápice agudos, coriácea, castanha, 4,5-8 ×1,5-2 cm; epicarpo híspido, rugoso, com protuberâncias na face externa, glabro, reticulado na face interna; endocarpo livre, castanho, coriáceo, ápice inteiro, viloso a tomentoso, tricomas castanhos, sedosos e briIhantes na face interna, parede lateral castanha, coriácea, lisa a ondulada; replum pendente, castanho-claro; funículos 2-6; valva navicular, dorso em seção transversal agudo, abertura de 0,5-2 $\mathrm{cm}$; sementes 2-6 por valva, orbiculares, tricomas enovelados, castanhos.

Distribuição geográfica: Guiana Francesa; Brasil nos estados do Roraima, Amapá, Pará e Rio de Janeiro.

Espécimes selecionados: GUIANA FRANCESA. "Cayenne", 1792, M. Leblond 36 (G); BRASIL. Roraima: Caracaraí, BR 174, 16.VI.1985, I. Cordeiro et al. 62 (INPA, NY); Amapá: Macapá, campo, 15.VII.1951, R.L. Fróes \& G.A. Black 27405 (IAN); Pará: Rio Guamá, Serraria, 11.I.1945, R.L. Fróes 20368 (IAN); Rio de Janeiro: Bacaxá, restinga de Jacarepiá, 20.IV.1994, J. Miguel 265․\& E. F. Guimarães (RB); Búzios, José Gonçalves, Serra das Emerências, 22049'S e 41057'-41058 'W, 5.VI.1998, J.M.A. Braga 4868 et al. (RB); Cabo Frio, Peró, 14.IX.2002, A. Quinet 728 \& F.F. Moreira (RB); Campos, III.1918, J. Sampaio 2901 (VEN); Macaé, 11.XII.1964, F. A. Trinta 1094 \& E. Fromm 2170 (HB, R, RB); Carapebus, restinga, 13.V.1995, M.G. Bovini 771\& L.C. Giordano (RB); Nova Iguaçu, Serra de Madureira, 14.VII.1985, J. R. Miguel 323 (RB); Rio de Janeiro, 1839, M. Guilhermin 689 (G); Ilha do Governador, 14.VII.1970, F.A. Trinta 994, E. Fromm 2070 (HB, R); Saquarema, 23.X.1990, M.C. Marques 216 (RB); Saquarema, Restinga, 18.I.2007, $R$. Marquete 4051 et al (RB); Rio das Ostras, VII.2004, A. Oliveira 965 (RB).

3.24. Trigonia virens Macbr., Publ. Field Mus. Nat. Hist. Bot.11(2) 68. 1931. Tipo: PERU. Loreto: Wooded banks of rio Itaya above Iquitos, 17-22.IX.1929, E. P. Killip \& A. C. Smith 29539 fl (Holótipo US!, Isótipo F, G, foto NY!, RB!). Fig. 2: a - e.

Cápsula trivalvar, unilocular, deiscência concomitante nas duas extremidades, lanceolada, base atenuada, ápice agudo, levemente acuminado, coriácea, castanha, 7-8 x 2,5-4,5 cm; epicarpo esparso-alvo-pubérulo, com nervuras salientes nas faces externa e interna; endocarpo aderente, castanho, coriáceo, ápice inteiro, glabro com sulco mediano; replum ereto, perceptível, funículos 12-18; valva foliácea, dorso em seção transversal plano, base e ápice agudos. Sementes 12-18 por valva, orbiculares-achatadas, tricomas $1,5 \mathrm{~cm}$ compr., eretos, castanho-amarelados.

Espécie que se caracteriza pelas folhas opostas com tricomas alvos na face abaxial. As flores apresentam anel estaminal desprovido de estaminódios. Ocorre na Colômbia, Peru, Brasil nos estados do Amazonas, Pará e Rondônia, em áreas de várzea ou matas de Igapó habitando solos argilosos.

Espécimes examinados: PERU. Maynas: Province Indiana, Reserva, 73005' W, 03030' S, alt. 108ms.m., 14.II.1990, R. Vásques et al. 13463 
(CEN, MO); BRASIL. Pará: Oriximiná, rio Paru do Oeste, 6.IX.1980, C.A. Cid et al. 2208 (INPA, MG); Acre: Rio Branco, Tamshiyacu, 17.III. 1978, C. Díaz et al. 196 (INPA); rio Yaguasyacu, 7.XI.1977, A. Gentry \& J. Revilla 20361 (F); Rio Yavari, 23.XI. 1977, A. Gentry \& J. Revilla 20867 ( $F$, INPA).

4. Trigoniastrum Miquel, Fl. Ned. Ind. 394, 1861. Tipo: Sumatra, Austr. In prov. Lampong, prope Mangala fl, fr (Lectotype U!, Bogor 4548, apud Lleras 1978).

Sâmara 3-5cm compr., obovada, trialada, alas unidas na porção basal, livres no ápice, base aguda, multinervadas, nervação promínula, coriáceas, castanhas, o lado interno reto, margem externa arredondada. Sementes uma por lóculo, obovadas, achatadas, velutínea, sem endosperma. Gênero monotípico, espécie típica

\subsection{T. hypoleucum Miquel}

5. Trigoniodendron E. F. Guim. \& Miguel, Rev. Brasil. Biol. 47 (4): 559-563. 1987. Tipo: BRASIL. Espírito Santo: Linhares, Reserva Florestal, Est. 154, talhão 507, 11.XI.1978, J. Spada 015/77 fl (Holótipo RB!). Fig. 2: p - s.

Cápsula trilocular, trivalvar, deiscência do ápice para a base, elíptica ou arredondada, base e ápice arredondados, coriácea, castanha, 1,1-1,8 $x$ 1,1-1,5 cm.; epicarpo rufo-viloso a glabrescente, lenticelado na face externa, glabro, com protuberâncias na face interna; mesocarpo espesso, reticulado, foveolado, aderente ao epicarpo; endocarpo livre, castanho, coriáceo, ápice bífido, glabro na face interna; parede lateral, castanha, coriácea, irregular; replum ereto, castanho; funículos 3-5; valva navicular, dorso em seção transversal arredondado, 0,3-0,5 cm de abertura; sementes 3-5 por valva, elípticas, tricomas 1,2-1,3 $\mathrm{cm}$ compr., enovelados a eretos, castanhos. Gênero monotípico. Figura II, p-s.

5.Trigoniodendron E. F. Guim. \& Miguel.

Tipo: BRASIL. Espírito Santo: Linhares, Reserva Florestal da Companhia Vale do Rio Doce, est. 154, km, 0,900, talhão 507, 11.XI.1977, J.Spada s.n. (Holótipo CVRD,RB).

Espécie caracterizada por ser árvore de folhas alternas; flores com anel estaminal desprovido de estaminódios. Endêmica do Brasil, nos estados do Espírito Santo e Rio de Janeiro. Ocorre em floresta ombrófila densa. Gênero monotípico, espécie típica

\subsection{Trigoniodendron spiritusanctense E.} F. Guim. \& Miguel.

Espécimes examinados: BRASIL. Espírito Santo: Linhares, Reserva Florestal da Companhia Vale do Rio Doce, 30ms.m., 26.IX.1978, G. Martinelli 5117 (Parátipo CVRD, RB!); estrada 154, 12.IV.1979, A.L. Peixoto 1050 (CVRD, RB); Rio de Janeiro: Barra de São João, Manguinhos, Fa- zenda São Pedro. Mata do Carvão, 28.XI.1995, H.C. de Lima,5282 (RB).

\section{Conclusões}

As Trigoniaceae apresentam-se como árvores ou arbustos eretos desenvolvendo-se em ambientes fechados no interior de matas ou como lianas geralmente encontradas em ambientes abertos, clareiras às margens de matas ou de estradas. O mecanismo de dispersão nos gêneros arbóreos não brasileiros Trigoniastrum, Humbertiodendon e Isidodendron tem suas sementes disseminadas juntamente com a sâmara trialada, enquanto nos brasileiros arbóreo Trigoniodendron e não arbóreo Trigonia, que dispõem de cápsulas dispersam suas mínimas sementes não acopladas ao fruto.

Em Trigonia a cápsula define táxons em níveis específicos e subespecificos entretanto não para todas as espécies. Este caráter permitiu reunir as espécies em 2 grupos: Um que apresenta cápsula monolocular, contendo $T$. virens e em $T$. hypoleuca; o outro com cápsulas triloculares que, por sua vez, se subdivide em dois subgrupos com base nos tipos de deiscências e replum. Um dos subgrupos apresenta a deiscência das valvas concomitante nas duas extremidades, com replum longo e flexível, formando seis cordões que se fixam a $1 / 3$ superior das valvas livres que ficam pendentes sendo aqui inseridas as espécies: $T$. cipoensis, T.fasciculata, $T$. nivea, $T$. rotundifolia, $T$. floccosa, $T$. villosa, $T$. sericea, T. killipii, T. spruceana e o outro subgrupo tem a deiscência do ápice para a base e o replum se apresenta ora visível e rígido, ora imperceptível e as valvas, neste caso, ficam presas pela base após a abertura, neste estão incluídos os táxons $T$. boliviana, $T$. simplex, $T$. paniculata, $T$. eriosperma, $T$. rytidocarpa, $T$. laevis, $T$. microcarpa, $T$. rugosa, $T$. bahiensis e Trigoniodendron espiritusanctense.

O estudo do fruto de um modo geral nesta família permitiu verificar a importância deste caráter no âmbito dos gêneros, espécies e variedades. Ressalta-se, não raro a facilidade para identificação em nível genérico, especialmente porque em sua maioria os mesmos são monoespecíficos, ao contrário de Trigonia que possui cerca de trinta espécies. Embora, neste último tenha sido possível estabelecer grupos e subgrupos com base nos tipos de replum e deiscências, por oportuno, verificou-se, que para elaboração da chave analítica, naquelas espécies morfologicamente similares, foi necessário adicionar outros caracteres ligados às folhas e flores.

As sementes pilosas, com tricomas unicelulares oriundos da testa e de coloração variada de amarelados a castanhos, echinados (Trigonia spruceana, T. killipii, T. virens e T. hypoleuca) ou enovelados e longos (Trigonia nivea, T. villosa, $T$. eriosperma, T. fasciculata e Trigoniodendron espiritusanctense), permitem informar que 
os tricomas que envolvem a semente sugerem a dispersão pelo vento, especialmente dada a relação deiscência/replum, que em algumas espécies ficam retidas e expostas quando as valvas ficam presas pela base, neste caso as sementes caem, pelo movimento capsular. Em outras espécies, em que as cápsulas ficam pendentes, uma adaptação que permite o movimento das valvas pelo vento o que favorece a disseminação.

Neste trabalho foram analisadas coleções dos séculos passados e deste, dos herbários nacionais e internacionais, muitas vezes representadas apenas pelo exemplar tipo. No Brasil as coleções examinadas demonstraram que há necessidade de coletas, especialmente para a região Norte, assinaladas não raro, por esparsas amostras.

\section{Agradecimentos}

Aos curadores dos herbários pelo empréstimo dos materiais; a FAPERJ pelo financiamento; ao CNPQ e a FUNADESP/PROPESQ pela concessão de bolsas de produtividade em pesquisa.

\section{Lista de Exsicatas}

Agra, M.J. 140 (3.13b); Alemão, F. 527 (VEM); Almeida, J. 1405 (3.5); Amorim, A. 925 (3.1); Andreata, R. 776 et al. (3.4); 76 (3.5); Andrade, P.M. \& Lopes, M.A. RB370715 (3.14); Andreata, R. et al 776 (3.4); Angeli, C. 528 (3.23c.); Araquistain, M. 3761 (3.18); F.S. de Araújo S.n - RB 324059 (3.1); Armond, N. 66 (3.13c); Assis L.C. \& Ladeira, M.K. 245 (3.21); Atkins, S.A. et al. 4876 (3.4); Aublet s.n. BM (3.10); Bang, A.M. 2191 (3.7); Barreto, M. 83702(3.7b); Bernardi, L.A. 7968 (3.12); Black, G. 47-932 (3.12); Black, G.A. \& Cordeiro, E. 52-15228 (3.18); Boone, W. 799 (3.13c); Boudet Fernandes, H.Q. et al.2529 (3.13b); Bovini, M.G. \& Giordano, L.C. 771 (3.23c); Bovini, M.G. et al 2510 (3.6), 2078, 2627 (3.13b); Brade, A.C. 6335 (3.13a), 13889 (3.13c); Brade, A.C. et al 18073 (3.14); Braga, J.M.A. 6649 (3.11), 4868 (3.23c). ; Braga, H. N. 899 (3.11); Brandão, M. 24137 (3.7b); Bunting, G.S. \& Fucci, M.8349 (3.18); Cabrera, 823 (2); Capuron, R. 18059SF (1); Cardoso, D. 988 (3.4); Cardoso, D. \& Ernane, 781 (3.5); Carneiro, J.L. et al 466 (3.13a); Carlos, L. et al. 1237 (3.9); Carreira, L. et al. 439 (3.9); Carvalho, L. d'A. F. de 157 (3.14); Carvalho, A.M. de et al 3911 (3.4); Castro, F.R.M. et al 385 (3.14), 630 (3.21); Casareto, G. 1956 (3.19); Chagas, J. RB197239 (3.23a), INPA 971 (3.23b); Cid Ferreira, C.A. 5225, 5553 (3.8), 8810 (3.9); 5484 (3.12), 5225 (3.15), 1328 (3.22), 11593 (3.23b), 2208 (3.24); Cordeiro, I. et al. 62 (3.23c); Cordeiro, M.R. 829 (3.9), 621 (3.12); Constantino, D. 805 (3.7) RB24392 (3.23c); Davidse, G. et al 15.590 (3.13c), 23297 (3.18); Díaz, C. et al. 196 (3.24); van Donselaar, J. 2891 (3.3); Duarte, A.P. 2040 (3.6), 4011 (3.10); 102 (3.13b), 8142 (3.13c); Duarte, A.P. \& Pereira, E. 4801 (3.14); Duarte, E. \& Castelhanos, A. 304 (3.13a); Ducke, A. S.n.-RB14448 (3.3), s.n.-RB47812 (3.12), s.n. -RB20278 (3.12) s.n. -RB14450 (3.13a), s.n. -RB23871 (3.23A); Ducke, J. \& Nickerson, N. 14914 (3.6); Elias, Bro 1105 (3.5); Farág P.R. et al. 254 (3.5); Farney, C. Gomes, J.C. 1264 (3.23c); Farney, C. et al 1303, 2233 (3.23c); Fernandes, A.P. \& Edilberto RB 292580 (3.6); Ferreira, M.C. 509 (3.6); Ferreira, C.A.C. 1654 (3.2), 5231 (3.12); Ferreira, M.C. \& Jost, T. 1062 (3.13c); Ferreira, V.F. 3063 (3.13a); Foll, D.A. 1062 (3.1); Fontella, J.P. 2266 (3.21); Fontella, J.P. 3012 \& Paixão, R. 44 (3.23c); Fontella, J.P. \& Vidal, R. 1006 (3.14); Fontella, J.P. et al 1007 (3.21), 3115 (3.23); Fróes, R.L. 20368 (3.23c); Fróes, R.L. \& Addison, G. 29067 (3.22); Fróes, R.L. \& Black, G.A. 27405 (3.23c); Fromm, E. 2070 (3.23c); Funch, L.S. \& Funch, R. 1132 (3.14); Furlan, A. 708 \& Castellanos 25.460 (3.6); Furlan, A. et al RB326887 (3.4); Ganev, W. 3182 (3.4); Gardner, G. 4461 (3.13c); Gentry, A. \& Cuadrons, H. 68186 (3.5); Gentry, A. \& Revilla, J. 20361, 20867 (3.24); Gentry, A. et al 29958 (3.15), 15849 (3.20); Glaziou, A.F.M. 9717 (3.2), 10730 (3.13a), 8670 (3.13c), 19688 (3.19); Góes, D.C. \& Constantino, D. 509 (3.14); 553 (3.10); Gomes, M. et al 559 (3.23c); Gomes, W. 3182 (3.7b); Gonzaga, L.C. 36 (13.c); Graham, J. \& Vigo, J.S. 423 (3.20); Grijalva, A. et al 3264,1000 (3.18); Guedes, M.L. et al 3844 (3.5); Guillemin, M. 654 (3.5), 689 (3.23c); Guillén, R. \& Chore, R. 2400 (3.12); Guimarães, E.F. \& Marques, M.C.M. 1732, 1741, 1742 (3.4), 1743 (3.6); Guimarães, E.F. et al 1714 (3.4); Harley, R.M. 16811 (3.6), RB22234 (3.14); Heringer, E.P. 878 (3.13b); Hermendoff, E. 87 (3.13a); Heyde, N.M. \& Lindeman J.C. 54 (3.12); Hoffman, B. 1355 (3.8); Hoffman, W.A. 79 (3.21); Killip,E.P. \& Smith, A.C. 29539 (3.24); Kollmann, J.G. et al 211 (3.21); Kollmann, L. et al. 2408(3.21); Krukoff, B.A. 10956 (3.12); Kuhlmann, J.G. 420 (3.5), 2065 (3.12), 2307 (3.14), 60 (3.23b); Lana, J. P. \& Castellanos, A. 24460 (3.13c); Landrum, L.R. 4143 (3.5); Leblond M. 36 (3.23c); Leoni, L.S. 1854 (3.7b); Liesner, R. 4157 (3.22); Liesner, R. \& Gonzalez, A.C. 5629 (3.23b); Lima, H.C de 1086 (3.13b); 5282 (5); Lima, H.C. de \& Lewis, G.P. 2833 (3.23c); Lima, H.C de \& Martinelli, G. 1739 (3.13b); Lima, H.C de et al 3072 (3.23c); Lima, J.C. de \& Santos, M.M. 154 (3.14); Lindberg, G.A. 748 (3.5); Lopes, M.A. \& Andrade, P.M. 279 et al (3.5); Lopes, M.A,. Matão, I.K. \& Andrade P.M. 345 (3.14); Lowrie, S.R. et al. 354 (3.20); MacDaniel, S. 16059 (3.3.); MacDaniel, M.S. \& Rimachi, M. 21103 (3.20); Machado, M. \& Oliveira, M.V.M. 174 (3.6); Machado, O. s.n. - RB 14451 (3.10); Magalhães, M. 9786 (3.7b); Maguire, B. \& Faughawe, D.B. 23192 (3.10); Marinho, L.R. 7 (3.23b); Marques, C.M. 242 (3.18), 216 (3.23c); Marquete, R. 1419 (3.13b); Marquete, R. \& Marquete, O. 1851 (3.5); Marquete, R. et al 3781 (3.5), 3388 (3.13b), 4051 (3.23c); Martinelli, G. 4754 (3.7b); 4710 (5), 5117 (5); Martinelli, G. \& 
Barbara, T. 15350 (3.13b); Martinelli, G. et al 6694 (3.6); Martinez, E. 18978 (3.3.); Martins, N.F. 124 (3.4); Matos Silva, L.A. et al. 2225 (3.12), 3018 (3.13b); Matuda, E. 17630(3.5), 16548 (3.18); Mello, R. et al 1835 (3.13c); Mexia, Y. 4705 (3.21); Miguel, J. 43, 63 (3.5), 271 (3.13a), 233, 234 (3.17), 323 (3.23c); Miguel, J. \& Gadoni, M. 477 (3.11); Miguel, J. \& Guimarães, E.F. 540, 541 (3.11), 365, 475 (3.13b), 265A (3.23c); Miguel, J. \& Demuner, V. 466 (3.14), 464 (3.19); Miguel, J. et al. 498 (3.13a), s.n.-RB433642 (13.c); Mikan, J.G. 5983 (3.4), 62 (3.9); Moreno, P. 2028 (3.18); Mori, S. \& Gracie, C. 21905, 22450 (3.22); Mori, S.A. \& Boom, B.M. 14334 (3.12); Mori, S A. \& Santos, T. S. 11777 (3.12); Mosén, H. 18 (3.21); Nascimento, O.C. 335 (3.12); Nee, M. 34553 (3.10); Neto, S. R. et al. 502 (3.10); Noblick, L.R. 2979 (3.13b); Novaes, C. 1108 (3.13a); Occhioni, P. 7945 (3.13a); Oldemann, 1979 (3.10); 2041 (3.23); Oliveira, A. 965 (3.23c); Oliveira, E. 4025 (3.12); Occhioni, P. 7003, 6872 (3.13b); Pabst, G.F. 4453 (3.9), 5438 (3.9), 7206 (3.9); Peixoto, A.L. 1050 (5); Pereira, E. 1246 (3.5), 102 (3.13b); Peron, M.V. et al 134 (3.21); Pifano, D.S. 382 (3.14); Pifano, D.S. \& Valente, A.S.M. s.n. CESJ 34126 (3.14); Pífano, D.S. et al 432 (3.13c); Pipoly J.J. et al. 8969 (3.10), 7600 (3.12); Pires, J.M. \& Silva, N.T. 4734 (3.3.); Pizziolo, W. 18 (3.21); Poncy, O. 277 (3.23c); Quinet, A. \& Moreira, F.F. 728 (3.23c); Regnel, A.F. 225 (3.13a); Riedel, L. 660 (3.19); Robledo, W. 239 (3.18); Rodrigues, W. 726 (3.22), 9009 (3.12); Rodrigues, W. et al 10281 (3.12); Rodrigues, I.A. et al 768 (3.23c); Sales, M.F. 425 (3.6); Sampaio, A.J. 6744 (3.4), 8754 (3.11); Sampaio, J. 2901 (3.23c); Sandino, J.C. 1965 (3.18); Sant'Ana, S.C. et al 539 (3.13b); Saturnino, H. 463 (3.1); Schott, H.W. 877, 5980 (3.19), 5982 (3.13c), 5978 (3.5); Schuck, P.J.F. 5985 (3.5); Schunke, J. 2299 (3.20); Schwacke, C.A.W. 6544 (3.14); Simão R. et al. s.n.-SPF42337, RB391477(3.7b); Silva, A.S.L. et al. 1941 (3.9); Silva, M. 20 (3.23b); Silva, M.G. 6442 (3.12); Silva, M.G. \& Rosário 4733 (3.12); Silva, M.G. \& Bahia, R. 3504 (3.5); Silva, M.N. 289-a (3.23b); Silva, R.M. et al. 1835 (3.13a); Silva, R. M. \& Pirani, J.R. 815 (3.21); Smith, L. B. 5795 (3.13c); Sobral, M. 4754 (3.1); Somner, G.V. et al 995 (3.19); Stevens, W.D. et al. 19074 (3.18); Stehmann, J.R. \& Mendonça, C.V.F. 34 (3.13c); Steinbach, J. 8132 (3.2); Steyermark, J.A. 74649 (3.20); Steyermark, J.A. \& Aristeguieta, L. 77 (3.16); Stoffers, A.L. et al. 112 (3.10); Sucre, D. \& Plowmann, T.C. 5129 (3.5); Sucre, D. et al. 2513 (3.2), 3607 (3.5), 10650 (3.13b); Tameirão Neto, E. 2509 (3.5); Tenório, E. \& Freitas, L. C. 2454 (3.4); Thomaz, L. B.D. 01 (3.21); Trinta, F. A. 1094 \& Fromm, E. 2170 (3.23c); Vasconcelos, M.F. \& D' Angelo Neto s.n.-RB 391300 (3.7b); Vasquez, R. \& Jaramilo, N. 8490 (3.20); Vasques, R. et al 21160 (3.12), 13463 (3.24); Vervolet, R.R. \& Baúsen, 165 (3.21); Vervolet, R.R. et al. 1129 (3.5), 758, 1973 (3.13b); Viana, M.C. 118 (3.13b); Vieira, J.N. s.n.RB60058 (3.19), 449 (3.21); Vieira, M.G. et al. 1054 (3.20); Williams L. 14770 (3.22); Zapi, D.C. et al. RB 326085 (3.4); RB 391476 (3.13c).

\section{REFERÊNCIAS}

Aublet, J.B.C.F. 1775. Trigonia in:- Histoire des plantes de la Guiane Françoise,... Londres, Paris (Pierre-François Didot jeune) v.1, p. 387392, t. 149-150.

Barroso, G. M., M. Pires Morim, A.L. Peixoto \& C.L.F. Ichaso. 1999. Frutos e sementes: morfología aplicada à sistemática de dicotiledôneas, Viçosa. Imprensa Universitária, U.F.V, 443.

Bentham, G. 1844. The botany of the voyage of H.M.S. Sulphur London (Smith, Elder\&co.) part. 4, 74 .

Bentham, G \& J. D. Hooker. 1867. Trigonia. in:Genera plantarum... London. (A. Black, William Pamplin, id Lovell Reeve \& Co., Willians \& Norgote) v.1, part.3, p. 977.

Cambessèdes, J. 1829. Trigonia. In: Saint-Hilaire, A.F.C.P.de Jussieu, A.H.L.de \& Cambessèdes, J. Flora brasiliae meridionalis... Parisiis. (apud A. Belin,...), v.2, part. 13 p.112-116.

Cambessèdes, J. 1830. Trigonia. In: Saint-Hilaire, A.F.C.P.de Jussieu, A.H.L.de \& Cambessèdes, J. Flora brasiliae meridionalis... Parisiis. (apud A. Belin,...), v.2, part. 14, pl.105.

Candolle, A. P. de. 1824. Hippocrateaceae. In:Prodromus systematis naturalis regni vege- tabilis. Paris (Treuttel et Würtz), Strasbourg, London, v.1, p.567-572.

Casareto, G. 1842. Trigonia rytidocarpa. In:-. Novarum Stirpium Brasiliensium Decades. Genova. (Typis Joannis Ferrandi), p.76.

Endlicher, S. L. 1840. Trigoniaceae. In:-. Genera Plantarum secundum ordines naturales disposita. Wien. (Fr. Beck), part. 14, p. 1080-1081.

Endlicher, S. L. 1841. Trigoniaceae. In:-. Enchiridion botanicum... Leipzig (W. Engelmann), Wien. (Fr. Beck et al.), p.570.

Fernández-Alonso, J. L., J. A. Pérez-Zabala \& A. Idarraga-Piedrahita. 2000. Isidodendron, un nuevo género neotropical de árboles de la familia Trigoniaceae. Revista da Academia colombiana de Ciencias Exatas, 34(92):347-357.

Glaziou, A.F.M. 1905. Trigoniaceae. In:-.Plantae Brasiliae centralis a Glaziou Lectae. Liste des Plantes du Brésil Central reguilées en 18611895. Memoires de la Societe Botanique de France. Paris. 1(3):1-112.

Grisebach, A.H.R. 1849. Trigoniaceae. In:-. Klotz, Beitrage zueiner flora der aequinoctial-gerender der neuen welt. Linnaea 22:27-31.

Guimarães, E.F. \& J.R. Miguel. 1980. Contribuição ao conhecimento das Trigoniaceae Brasi- 
leiras. IV- Uma nova variedade para o Amazonas - Trigonia villosa var. duckei Guimarães \& Rodrigues Miguel. Rodriguésia 32(54):41-47. est. 1-3.

Guimarães, E.F. \& J.R. Miguel. 1985. Flora do Estado do Rio de Janeiro-família Trigoniaceae. Rio de Janeiro, Brasil. Rodriguésia 37(63):5772, est.1-19c.

Guimarães, E.F. \& J.R. Miguel. 1987. Contribuição ao conhecimento de Trigoniaceae Brasileiras VI - Trigoniodendron Guimarães \& J. Miguel. n. gen. Rio de Janeiro, Brasil. Revista Brasileira de Biologia, 47(4):559-563, fig. 1-14.

Guimarães, E.F., C.G. Costa \& J.R. Miguel. 1984. Trigoniaceae Brasileiras V. Sobre a validade de Trigonia microcarpa Sagot ex Warming. Rio de Janeiro, Brasil. Rodriguésia 36(36):51-56, fig. 1-5.

Guimarães, E.F, J.R. Miguel \& J.F. Pereira. 1979. Contribuição ao conhecimento das Trigoniaceae brasileiras. II. Uma nova espécie do Estado da Bahia. Boletim Museu Botânico Municipal Curitiba. 36:3.

Kunth, C.S. 1822. Trigonia. In: Humboldt, F.W.H.A. von; Kunth, C.S. \& Bonpland, A.J.A. Nova genera et species plantarum... Lutetiae Parisiorum, [Paris]. (Sumptibus librariae graeco-latini-germanicae...), v.5, p.141-142.

Lamarck, J.B.A.P.M. de. 1783. Croton eriospermum. In:-. Encyclopedie méthodique, Botanique... A. Paris. (Chez Panckoucke,...), Liège (Chez Plomteux,...)v.1, part. 1, p.1-344.

Lamarck, J.B.A.P.M. de. 1792. Trigonia In:- Tableau encyclopédique et méthodique des trois règnes de la nature. Botanique... Paris (Chez Pancoucke,...) v.1, part. 2; t. 347.

Leandri, J. 1949. Sur la presence d'une Trigoniacée dans la flora Malgache. Comptes rendus hebedomadaires des séances de l'académie des sciences. Paris 229: 846-848.

Lleras, E. 1978. Trigoniaceae. In:-. Flora Neotropica. Monograpph Organization for Flora Neotropica. New York Botanical Garden. v.모, 1-73. 19 figs.

Lleras, E. 1982. Uma nova Trigonia da flora amazônica. Acta amazônica 12(2):293-294, 1 fig.

Macbride, J. F. 1931. Spermatophytes, mostly peruvian-III. Field Museum of Natural History - Botanical Series 9(1):68-69.

Macbride, J. F. 1950. Trigoniaceae In Macbride, Flora of Peru. Field Museum of Natural History - Botanical Series. 13 (3):950-954.

Miguel, J.R. \& E.F. Guimarães. 1994. Contribuição ao conhecimento das Trigoniaceae brasileiras IX. Ocorrência e nova variedade para Trigonia floccosa Rusby em Minas Gerais.

Miguel, J.R. \& E.F. Guimarães. 1994. Contribuição ao conhecimento das Trigoniaceae brasileiras X. O fruto de Trigonia rotundifolia Lleras. Acta Botanica Brasilica, Secção Rio de Janeiro. 3(17):125-128, 1 foto.
Miguel, J.R. \& E.F. Guimarães. 1994. 2000. Trigoniaceae brasileiras XIII - Restabelecimento de um táxon e descrição de uma nova espécie. Bradea 8 (32):197-200 1 fig.

Miguel, J.R., E.F. Guimarães \& E. Lleras. 1993. Contribuição ao conhecimento das Trigoniaceae brasileiras VII. Uma nova variedade para Trigonia. Daphne. 3(4):7-10. 3 fotos. Belo Horizonte. Daphne.4(1):7-7. Belo Horizonte.

Petersen, O.G. 1896. Trigoniaceae. in: E.P., Die Natürlichen Pflanzenfamilien, Leipzig. (Wilhelm Engelmann), v.3(4):309-311, fig. 165166.

Perrier, H \& J. Leandri. 1955. Trigoniacées. in: Humbert, Flore de Madagáscar; 108(bis):1-4.

Pio-Correa, M. P. 1984. Dicionário das plantas úteis do Brasil e das exóticas cultivadas. Rio de Janeiro, Brasil. Ministério da Agricultura, v.2, p. 290.

Pio-Correa, M. P. \& L.A. Penha. 1984. Dicionário das plantas úteis do Brasil e das exóticas cultivadas. Rio de Janeiro, Brasil. Ministério da Agricultura. v.5, p.289.

Reitz, P. R. 1967. Trigoniáceas. In: Reitz, P.R. (Ed.). Flora Ilustrada Catarinense, Fasc. TRIG, 3:1-10. 2 figs.

Rusby, H. H. 1907. An Enumeration of the Plants Collected in Bolívia by Miguel Bang. Part $4^{a}$. Bulletim of the New York Botanical Gardem. v.4, 14:309-325.

Stafleu, F. A. 1951. Trigoniaceae, in Pulle, A. (Ed.) Flora Suriname; v.3, (2):173-177.

Thiers, B. 2009. [Continuously up dated]. Index herbariorum: A global directory of public herbaria and associated staff. New York Botanical Garden's Virtual Herbarium. http://sweetgum. nybg.org/ih/

Trinta, E.F. \& E. Santos. 1971. Nova Combinação no Gênero Trigonia Aubl. Boletim do Museu Nacional do Rio de Janeiro. 41:1-3.

Trinta, E.F. \& E. Santos. 1981. Uma nova espécie do gênero Trigonia Aubl. (Trigoniaceae). Bradea Boletim do Herbário Bradeanum. 3(20):145-147.

Vahl, M. 1798. Trigonia Aubl. in:-. Eclogae Americanae seu descriptions plantarum praesertium Americae meridionalis, nondum cognitarum.... Hauniae [København], (Imprensis auctoris. Excudebant Nicolaus Möller et fillius...) v.2, p I-vi], 52-54, pl. 11-20.

Warming, E. 1875. Trigoniaceae. In: Martius, C.F.P. von; Eichler, A.W.\&Urban, I. (Eds.). Flora brasiliensis,....Minchen, Wien, Leipzig, v. 13, part. 2, p.118-144. t.22-27.

Recebido em 05.IX.2013 Aceito em 27.III.2014 